OPEN ACCESS

Edited by:

Weifeng Zhao,

Sichuan University, China

Reviewed by:

Dongsheng Wang,

University of Electronic Science and

Technology of China, China

Tao Xiang,

Southwest Jiaotong University, China

*Correspondence:

Guoping Chen

Guoping.Chen@nims.go.jp

Specialty section:

This article was submitted to

Polymer Chemistry,

a section of the journal

Frontiers in Chemistry

Received: 31 July 2018 Accepted: 01 October 2018 Published: 22 October 2018

Citation:

Li X, Sun Q, Li Q, Kawazoe N and Chen $G$ (2018) Functional Hydrogels

With Tunable Structures and

Properties for Tissue Engineering

Applications. Front. Chem. 6:499.

doi: 10.3389/fchem.2018.00499

\section{Functional Hydrogels With Tunable Structures and Properties for Tissue Engineering Applications}

\author{
Xiaomeng $\mathrm{Li}^{1,2}$, Qingqing Sun ${ }^{3}$, Qian $\mathrm{Li}^{1,2}$, Naoki Kawazoe ${ }^{4}$ and Guoping Chen ${ }^{4 *}$ \\ ${ }^{1}$ School of Mechanics and Engineering Science, Zhengzhou University, Zhengzhou, China, ${ }^{2}$ National Center for International \\ Joint Research of Micro-nano Moulding Technology, Zhengzhou University, Zhengzhou, China, ${ }^{3}$ Center for Functional Sensor \\ and Actuator, National Institute for Materials Science, Tsukuba, Japan, ${ }^{4}$ Research Center for Functional Materials, National \\ Institute for Materials Science, Tsukuba, Japan
}

Tissue engineering (TE) has been used as an attractive and efficient process to restore the original tissue structures and functions through the combination of biodegradable scaffolds, seeded cells, and biological factors. As a unique type of scaffolds, hydrogels have been frequently used for TE because of their similar 3D structures to the native extracellular matrix (ECM), as well as their tunable biochemical and biophysical properties to control cell functions such as cell adhesion, migration, proliferation, and differentiation. Various types of hydrogels have been prepared from naturally derived biomaterials, synthetic polymers, or their combination, showing their promise in TE. This review summarizes the very recent progress of hydrogels used for TE applications. The strategies for tuning biophysical and biochemical properties, and structures of hydrogels are first introduced. Their influences on cell functions and promotive effects on tissue regeneration are then highlighted.

Keywords: functional hydrogels, tissue engineering, physical properties, chemical properties, microstructures

\section{INTRODUCTION}

Tissue engineering (TE) has emerged as a useful approach to treat tissue damages caused by diseases and trauma, which has shown many advantages as compared to conventional treatment strategies. To afford desirable therapeutic outcome, scaffolds prepared from various kinds of biomaterials have been used for TE to accommodate sufficient amount of cells and to control cell functions (Chen and Kawazoe, 2016a,b; Chen et al., 2018).

Among of different types of scaffolds, hydrogels have attracted more and more attention in the TE field owing to their similarity to in vivo cellular microenvironment and tunable physiochemical properties (Drury and Mooney, 2003). Hydrogels are generally prepared by translating hydrophilic polymers solution into 3D network structure via physical or chemical crosslinking. During this process, hydrogels can encapsulate cells homogeneously and provide cells a 3D microenvironment similar to the native extracellular matrix (ECM) (Tibbitt and Anseth, 2009). Cell behaviors and functions in vivo are affected by the stimuli that are produced by the surrounding ECM. In a similar way, the structures and physiochemical properties of hydrogels provide critical cues to control the functions of embedded cells and thus guide tissue regeneration.

The structures and physiochemical properties of hydrogels can be designed and controlled through selecting different biomaterials, crosslinking methods and fabrication strategies. This review summarizes the latest developments of functional hydrogels for TE applications. At first, the 
materials and crosslinking methods used for hydrogel preparation are introduced. And then, the approaches to tune the structure and physiochemical properties of hydrogels and their effects on cell functions and tissue regeneration are compared. Finally, the challenges and future perspectives of functional hydrogels are discussed.

\section{MATERIALS AND CROSSLINKING METHODS FOR FUNCTIONAL HYDROGELS PREPARATION}

There are several criterias to prepare hydrogels for TE applications. Firstly, the materials and crosslinking agents should be compatible toward living cells and biological factors (e.g., growth factors). Secondly, the preparation process should be easily occured under mild conditions. Thirdly, the products from hydrogel degradation should be non-toxic to cells and tissues. The materials and crosslinking methods used for hydrogel preparation for TE are summarized in Table 1.

\section{Hydrogel Construction Materials}

Materials used to prepare TE hydrogels can be briefly classified into natural and synthetic polymers. Hydrogels prepared from natural polymers possess intrinsic advantages, such as high biocompatibility, biodegradability and similar microenvironment to that of native tissues. Natural polymers used for hydrogel preparation include protein-based materials (such as gelatin, collagen, fibrin, and silk fibroin) and polysaccharide-based materials (such as hyaluronic acid (HA), chondroitin sulfate (CS), alginate, chitosan and so on). Collagen, as the main ECM component of various tissue, is an attractive material for hydrogels preparation (Heo et al., 2016). It's derivative, gelatin, is also a frequently used protein-based material for hydrogel formation, which has higher solubility and lower cost when compared with collagen (Zhao et al., 2016). Gelatin-based hydrogels are good candidates for various TE. For example, injectable gelatin methacryloyl (GelMA) hydrogels are prepared for cartilage TE (Li et al., 2016). The chondrocytes 3D cultured in these hydrogels have shown excellent viabilities and desirable functions. HA as a glycosaminoglycan is commonly prevalent in body liquid and native ECM (Shendi et al., 2016). Therefore, it has been used to prepare various kinds of hydrogels for cartilage, skin, and many other TE. For example, it has been reported that HA molecular can bond with mesenchymal stem cells (MSCs) through CD44 receptors and promote the chondrogenesis (Chung and Burdick, 2008). CS is a sulfated glycosaminoglycan with a linear structure existing in cartilage tissue ECM (Levett et al., 2014). Chondrocytes cultured in CS hydrogels have round morphology, enhanced gene expression, and secretion of cartilaginous ECM (Levett et al., 2014; Zhu et al., 2014). Other polysaccharide-based materials, such as alginate (obtaining from bacteria and brown seaweed) and chitosan (derived from chitin that is produced from the shells of crabs and shrimps), are also commonly used for hydrogel preparation due to their biocompatibility, degradability and easy modification (Kim et al., 2016; Hunt et al., 2017).
On the other hand, synthetic polymers have also exhibited wide usage due to their controllability, reproducibility, and good mechanical properties (Guan et al., 2017). Representative synthetic polymers used for TE hydrogels include poly(ethylene glycol) (PEG), poly(vinyl alcohol) (PVA), poly (N-isopropylacrylamide) (PNIPAM) (Haq et al., 2017), and polyacrylamide (PAM) (Darnell et al., 2013). PEG and PVA have low toxicity, making them widely used for cell-laden hydrogels and drug carriers (Kim et al., 2016; You et al., 2018). However, due to the lack of biological activity, the biocompatibility of these synthetic polymers is compromised relative to natural materials. Hybridization with natural materials is an efficient and easy-going approach to integrate the advantages of natural and synthetic component. It has been reported that the biocompatibilities of PAM, PVA, PNIPAM, and PEG hydrogels are significantly improved after blend with gelatin (Gao et al., 2015; Kim et al., 2016; Navaei et al., 2016b; Han et al., 2017). The cell spreading, and proliferation in these hybrid hydrogels are enhanced compared with the cells 3D cultured in synthetic hydrogels. Besides, the hybridization of different natural materials can also exhibit novel attractive properties. For example, alginate is interpenetrated and crosslinked into photopolymerized gelatin hydrogel network to generate alginate/gelatin hybrid hydrogel (Pacelli et al., 2018). Such a hydrogel is confirmed to have the function of promoting bone tissue regeneration due to the good biocompatibility and enhanced mechanical property.

\section{Crosslinking Methods}

There are various methods for crosslinking of hydrophilic polymers chains to form hydrogels, which usually are selected depending on the materials chemistry and expected functions. In general, they can be classified into physical and chemical crosslinking methods.

\section{Physical Crosslinking Methods}

Physically crosslinked hydrogels can be prepared at very mild conditions without the utilization of crosslinking agents that often cause toxicity to cells or may affect the activity of biological molecules encapsulated in hydrogels (Hennink and Van Nostrum, 2012). There are many methods to prepare physically crosslinked hydrogels for TE applications, such as ionic interaction, guest-host interaction and thermo-gelation.

\section{Ionic crosslinking}

Ionic crosslinking method is frequently used to encapsulate cells and drugs due to the mild crosslinking procedures (Goosen et al., 1985; Gombotz and Wee, 2012). The most representative hydrogels formed by ionic crosslinking is alginate hydrogel. The crosslinking is through the exchange of sodium ions from guluronic acid units with divalent cations such as calcium to form junction zones (Gacesa, 1988). This physically crosslinked alginate hydrogel not only has shown a biocompatible property but also has many other functions, such as self-healing and stress relaxation, due to the reversible dissociation and re-bonding between $\alpha$-L-guluronic acid in alginate and calcium ions. However, the stability of ionic hydrogel should be considered 
TABLE 1 | Materials and crosslinking methods for functional hydrogels preparation.

\begin{tabular}{|c|c|c|c|c|c|c|}
\hline \multicolumn{3}{|c|}{ Materials } & \multicolumn{2}{|c|}{ Crosslinking methods } & \multirow[t]{2}{*}{ TE applications } & \multirow[t]{2}{*}{ References } \\
\hline & & Characteristics & $\begin{array}{l}\text { Physical } \\
\text { crosslinking }\end{array}$ & $\begin{array}{l}\text { Chemical } \\
\text { crosslinking }\end{array}$ & & \\
\hline \multirow[t]{18}{*}{ Natural Materials } & Gelatin & & Guest-host & & Cartilage TE & Feng et al., 2016 \\
\hline & & GelMA & & Photo & Cartilage, tendon TE & $\begin{array}{l}\text { Yang et al., 2016; Li et al., } \\
\text { 2017b }\end{array}$ \\
\hline & & GelMA & Thermal & Photo & Corneal TE & Rizwan et al., 2017 \\
\hline & & $\begin{array}{l}\text { Gelatin-hydroxyphenylpropionic } \\
\text { acid (Gtn-HPA) }\end{array}$ & & Enzymatic & Cartilage TE & $\begin{array}{l}\text { Wang et al., 2014; Le Thi } \\
\text { et al., } 2017\end{array}$ \\
\hline & Collagen & & & Photo & Meniscus TE & Heo et al., 2016 \\
\hline & $\mathrm{HA}$ & Adamantane-functionalized $\mathrm{HA}$ & Guest-host & & Cartilage TE & Wei et al., 2016 \\
\hline & & HA-vinyl sulfone & & Michael addition & Neural engineering & Shendi et al., 2016 \\
\hline & & $\begin{array}{l}\text { Maleimide-functionalized } \mathrm{HA} \text { and } \\
\text { furan-functionalized } \mathrm{HA}\end{array}$ & & Diels-Alder & Adipose TE & Fan et al., 2015a \\
\hline & & Methacrylated HA (MeHA) & & Photo & $\begin{array}{l}\text { Meniscus, nucleus } \\
\text { pulposus TE }\end{array}$ & $\begin{array}{l}\text { Kim et al., 2015; Koh } \\
\text { et al., } 2017\end{array}$ \\
\hline & $\begin{array}{l}\text { Chondroitin } \\
\text { sulfate }\end{array}$ & $\begin{array}{l}\text { Furfurylamine grafted chondroitin } \\
\text { sulfate }\end{array}$ & & Diels-Alder & Bone TE & Bai et al., 2017 \\
\hline & & Methacrylated chondroitin sulfate & & Photo & Cartilage TE & $\begin{array}{l}\text { Levett et al., 2014; } \\
\text { Abbadessa et al., } 2016\end{array}$ \\
\hline & Alginate & & Ionic & & $\begin{array}{l}\text { Cartilage, retinal and } \\
\text { bone TE }\end{array}$ & $\begin{array}{l}\text { Chaudhuri et al., 2016; } \\
\text { Hunt et al., 2017; Lee } \\
\text { et al., } 2017\end{array}$ \\
\hline & & Methacrylated alginate & & Photo & Bone TE & Ho et al., 2016 \\
\hline & Dextran & $\begin{array}{l}\text { Dextran bifunctionalized with } \\
\text { methacrylate and aldehyde }\end{array}$ & & Photo & Vascular TE & Liu and Chan-Park, 2009 \\
\hline & & $\begin{array}{l}\text { Azadibenzocyclooctyne-modified } \\
\text { dextran and azide-modified dextran }\end{array}$ & & Alkyne-azide & Cartilage TE & Wang et al., 2017b \\
\hline & Agarose & & Thermal & & Osteochondral, skin TE & $\begin{array}{l}\text { Sheehy et al., 2013; } \\
\text { Miguel et al., } 2014\end{array}$ \\
\hline & Chitosan & $\begin{array}{l}\text { Chitosan-g-poly(N- } \\
\text { isopropylacrylamide) }\end{array}$ & Thermal & & Cardiac, cartilage TE & $\begin{array}{l}\text { Baei et al., 2016; Mellati } \\
\text { et al., } 2017\end{array}$ \\
\hline & & Methacrylated glycol chitosan & & Photo & Bone TE & Kim et al., 2016 \\
\hline \multirow[t]{13}{*}{$\begin{array}{l}\text { Synthetic and } \\
\text { Hybrid Materials }\end{array}$} & PEG & Norbornene-terminated PEG & & Michael addition & Cartilage, vascular TE & $\begin{array}{l}\text { Mahadevaiah et al., 2015; } \\
\text { Sridhar et al., 2015; Wang } \\
\text { et al., 2017a }\end{array}$ \\
\hline & & $\begin{array}{l}\text { Thiol-norbornene PEG, PEG } \\
\text { diacrylate (PEGDA) }\end{array}$ & & Photo & $\begin{array}{l}\text { Cartilage TE } \\
\text { Heart valve TE }\end{array}$ & $\begin{array}{l}\text { Zhang et al., 2015; } \\
\text { Neumann et al., } 2016\end{array}$ \\
\hline & PAM/Gelatin & PAM and GelMA & & Photo & Cartilage TE & Han et al., 2017 \\
\hline & PVA/Gelatin & & Thermal & & Cartilage TE & Kim et al., 2016 \\
\hline & PNIPAM/Gelatin & $\begin{array}{l}\text { PNIPAAm-based copolymer, } \\
\text { thiol-modified gelatin }\end{array}$ & Thermal & Michael addition & Cardiac TE & Navaei et al., 2016b \\
\hline & PEG/Gelatin & PEG dimethacrylate, GelMA & & Photo & Bone, cartilage TE & Gao et al., 2015 \\
\hline & PEG/Chitosan & $\begin{array}{l}\text { Glycol chitosan, benzaldehyde } \\
\text { functioned PEG }\end{array}$ & & Schiff-base & $\begin{array}{l}\text { Neural engineering, } \\
\text { vascular TE }\end{array}$ & $\begin{array}{l}\text { Tseng et al., 2015; Hsieh } \\
\text { et al., } 2017\end{array}$ \\
\hline & PEG/HA & $\begin{array}{l}\text { Amino-terminated PEG, aldehyde } \\
\text { HA }\end{array}$ & & Schiff-base & Adipose TE & Fan et al., 2015b \\
\hline & & $\begin{array}{l}\text { Furylamine and tyramine functional } \\
\text { HA; Dimaleimide PEG }\end{array}$ & & $\begin{array}{l}\text { Diels-Alder/ } \\
\text { Enzymatic }\end{array}$ & Cartilage TE & Mahadevaiah et al., 2015 \\
\hline & Gelatin/HA & GelMA/MeHA & & Photo & Skin, neural TE & $\begin{array}{l}\text { Eke et al., 2017; } \\
\text { Magarinos et al., } 2018\end{array}$ \\
\hline & Gelatin/Alginate & Oxidized alginate, gelatin & & Schiff-base & Muscle TE & Baniasadi et al., 2016 \\
\hline & & GelMA and alginate & & Photo & Bone TE & $\begin{array}{l}\text { Lewandowska-Łancucka } \\
\text { et al., } 2017\end{array}$ \\
\hline & & GelMA, alginate & Ionic & Photo & Bone TE & Pacelli et al., 2018 \\
\hline
\end{tabular}


when using under physiological conditions. For instance, calcium crosslinked alginate hydrogel will lose stability in $0.9 \mathrm{wt} \%$ sodium chloride solution due to the exchange of calcium ions by sodium ions (Martinsen et al., 1989).

\section{Guest-host chemistry}

The guest-host chemistry holds great potential for hydrogels preparation, because the low cytotoxicity and specific selectivity. In this reaction, host molecules can selectively recognize and physically bind to certain guest molecules to form crosslinked network. The interaction includes hydrophobic association, hydrogen bonding, electrostatic interaction, van der Waals forces, and so on (Steed et al., 2007). Cyclodextrin, as one macrocycle, has hydrophobic interior cavities that have a high affinity for specific hydrophobic guest moieties. Specifically, guest-host pair, adamantane (guest) and $\beta$ cyclodextrin (host), is widely used to synthesize corresponding macromers. The guest-host bonding can translate mixed solution into hydrogels easily (Rodell et al., 2016). In another study, acrylate $\beta$-cyclodextrin can build guest-host binding with the benzene ring of gelatin to form supramolecular hydrogels. These hydrogels have very good bio-adhesive property and sustainable release of hydrophobic drugs, which is promising for TE of bone, cartilage and tendon (Feng et al., 2016).

\section{Thermo-gelation}

Thermo-gelation is to build a physically crosslinked network by altering the temperature. For example, the crystalline nature of PVA has been applied to fabricate physically crosslinked hydrogel by several repeating cycles of freezing and thawing (Hassan and Peppas, 2000). These physically crosslinked PVA hydrogels are reported to have many characteristics, such as high swelling degree and mechanical strength. Gelatin solution becomes hydrogel due to the intermolecular hydrogen bonding formation when the temperature drops below the upper critical solution temperature (UCST). In contrast, some other macromer, such as PNIPAM, becomes hydrogel when temperature increases above the lower critical solution temperature (LCST) due to the balance between hydrogen bonding and hydrophobic effects (Ashraf et al., 2016). These temperature-responsive polymers can transform phases between sol and gel near physiological temperature, which enables the hydrogels injectable. PNIPAMbased injectable hydrogel has been used to encapsulate cardiomyocytes and the encapsulated cells exhibit high viability and mature phenotypes (Navaei et al., 2016b).

\section{Chemical Crosslinking Methods}

Chemically crosslinked hydrogels have a better performance at stability than physically crosslinked hydrogels due to stronger binding energy and substantially improved flexibility. Hydrogelforming water-soluble polymers have many functional groups, such as $\mathrm{OH}, \mathrm{COOH}$, and $\mathrm{NH}_{2}$. 3D network can be established by covalent bonding between these functional groups using glutaraldehyde and EDC/NHS (Balakrishnan et al., 2013; Omobono et al., 2015; Cheaburu Yilmaz et al., 2017). However, the toxicity of crosslinking agents and process limit the TE applications. For example, small molecular crosslinkers like glutaraldehyde and carbodiimides have been reported to be toxic and are not recommended to fabricate cell-laden hydrogels (Balakrishnan, 2016). To meet the requirements for TE, several available strategies for functional hydrogel preparation will be discussed below.

\section{Photopolymerization}

Photopolymerization has been widely used for hydrogel fabrications due to its biocompatibility and spatiotemporal controllability. Usually, macromers are modified with photoreactive moieties, such as methacrylate or acrylate groups. The photoreactive macromer solution with photoinitiator can be crosslinked under UV or visible light. The photoinitiators can generate free radicals that are transferred to the photoreactive carbon double bond groups in the modified macromers to start chain polymerization. However, under high photo exposure, photoinitiator will generate a large number of free radicals which may react with intracellular molecules to induce cell damage. This problem can be addressed by decreasing the light energy and amount of photoinitiator (Bryant et al., 2000; Fedorovich et al., 2009). High density of methacrylate groups has been reported to protect encapsulated cells by quenching free radicals (Bartnikowski et al., 2015). The method can be used for the preparation of hydrogels from various kinds of polymers and a variety of cell types can be encapsulated into the hydrogels for TE applications (Park et al., 2003; Chen et al., 2018). One of the most frequently used macromers is GelMA, which retains cell adhesive peptide sequence (arginine-glycine-aspartic acid, RGD) and matrix metalloproteinase (MMP) degradable peptide (Yue et al., 2015).

\section{Enzyme-enabled crosslinking}

Enzyme-enabled crosslinking is highly selective for a specific enzyme and can be achieved under mild physiological conditions (Ulijn, 2006). Transglutaminase and horse radish peroxidase are two commonly used enzymes. Transglutaminase catalyzes trans-amidation reaction that introduces $\mathrm{N} \epsilon-(\gamma$-glutamyl)lysine cross-links in proteins, converting protein solution into $3 \mathrm{D}$ hydrogel network (Chen et al., 2003). Horse radish peroxidase can build networks between polymers by oxidative coupling of hydroxyphenylpropionic acid moieties (Wang et al., 2014). Besides selectivity, this enzyme-mediated crosslinking approach also exhibits rapid gelation and easily tunable mechanical properties by varying the concentration of horse radish peroxidase and $\mathrm{H}_{2} \mathrm{O}_{2}$ (Ren et al., 2015).

\section{Click chemistry}

Click chemistry has the characters of high efficiency, high yield, and proceeding with no side products, which make the method wildly studied. TE application requires the reaction to proceed under physiological conditions. The typical click reaction is thiol-ene radical reaction which is hindered by inhibitory capacity of oxygen and shows complicated volume relaxation and stress development compared with classical radical photopolymerization (Hoyle and Bowman, 2010). Other representative chick chemistry includes Diels-Alder reaction, 
azide-alkyne cycloaddition chemistry (Xu and Bratlie, 2018) and Michal addition. Strain-promoted azide-alkyne cycloaddition (SPAAC) click chemistry has drawn increasing attention recently due to the mild reaction conditions and bioorthogonality (Xu et al., 2014). An injectable and degradable PEG-based hydrogel has been prepared via the bioorthogonal SPAAC click chemistry (Jiang et al., 2015). Michael addition reaction is the nucleophilic addition of a carbanion or a nucleophile to an $\alpha, \beta$-unsaturated carbonyl compound. Michael addition-mediated hydrogels can be prepared under physiological conditions, making this kind of hydrogels injectable (Sun et al., 2017). For example, HA with thiol functional groups can form a 3D network with PEG vinysulfone macromers via Michael addition. The gelation time can be controlled by the degree of functionalization and the ratio of the two functional groups (Jin et al., 2010).

\section{Schiff base reaction}

Schiff base reaction has been widely used to form hydrogels via the coupling between aldehyde and amine groups in polymer chains. These hydrogels have been reported to have self-healing capacity due to the dynamic equilibrium of the linkages. For example, glycol chitosan and benzaldehyde functioned PEG have been synthesized and used to form a hydrogel with self-healing property for central nervous regeneration (Tseng et al., 2015). Proliferation rate and differentiation tendency of neurospherelike progenitors are enhanced in the self-healing hydrogel.

The above-described materials and crosslinking reactions have their respective merits and demerits. While, rational combination of natural and synthetic polymers or different crosslinking methods may afford an optimized approach to improve the hydrogel functions. For example, enzymatic crosslinking and Diels-Alder click chemistry can be induced into HA/PEG hydrogels for cartilage TE (Mahadevaiah et al., 2015). Both biocompatibility and mechanical property are improved by blending of HA and PEG polymers. The enzymatic crosslinking provides a suitable gelation speed for injectability, while the click reaction generates second crosslinking that renders an outstanding shape memory and anti-fatigue property. All these characters are required for cartilage TE.

\section{CONTROL OF PHYSICAL PROPERTIES}

Physical properties of hydrogels, such as mechanical strength, stiffness, stress relaxation, self-healing, and degradation, can be controlled at different levels to meet the specific requirements for TE. These physical properties have obvious effects on cell functions, and thus should be investigated and reviewed. The hydrogels prepared with different physical properties, and their effects on cell functions, as well as their applications for TE are summarized in Table 2.

\section{Mechanical Strength and Stiffness}

Conventional hydrogels normally possess breakable characters that will decrease their stability and thus cannot be utilized for specific tissue application such as bone, cartilage and tendon. To overcome this issue, two effective strategies have been developed. One is the hybridization of hydrogels with other polymers, nanoparticles or nanofibers. For example, regenerated silk fibroin and chitin nanofiber have been used to improve the mechanical strength of GelMA hydrogels by $\beta$-sheet folding and selfassembly, respectively. The hydrogel elastic modulus increases by one-thousand folds and strain-to-failure enhances by around $200 \%$ after chitin nanofiber assembly (Hassanzadeh et al., 2016). The hydrogels also demonstrate good cell viability, promotive cell differentiation and stable vasculature formation. Collagen-based hydrogels with a 10-fold increase in stiffness have been realized after mixing with very low amount of chemical functionalized nanoparticles working as crosslinker epicenters to make collagen chains crosslinked on the surface of nanoparticles (Jaiswal et al., 2015). Due to the interaction between nanoparticles and polymer chains, the mechanical properties of hybrid hydrogels can be enhanced. The other strategy is to prepare interpenetrating polymer network (IPN) hydrogels with high resistance to wear and high fracture strength, which has gained a lot of attention recently (Dragan, 2014). Double networks (DN) are introduced in hydrogels to enhance mechanical property for cartilage TE (Gong et al., 2003; Yasuda et al., 2009; Fukui et al., 2014). The feature of DN hydrogels is the formulation of first densely crosslinked hydrogel and second loosely network. The first network serves as sacrificial bonds to disperse the stress, while the second polymer chains work as hidden length that can extend to sustain large deformation (Haque et al., 2012). Similarly, ionic crosslinked chitosan with low molecular weight is used to work as the second crosslinking component to enhance the mechanical strength of the UV initiated PAM hydrogel (Yang et al., 2018).

Macroscopically, the mechanical property is important to maintain the scaffold stability to bear loads and fulfill the defects. Meanwhile, at microscopic level, the mechanical signals play a critical role in affecting cell activities and fates. For example, matrix stiffness has been reported to affect cell spreading, migration, proliferation and differentiation (Wen et al., 2014). Stiffness of hydrogels can be tuned by changing the crosslinking density, crosslinker length and molecular weight of the precursors (Slaughter et al., 2009; Li et al., 2016, 2017b). Differentiation of mesenchymal stem cells (MSCs) cultured on 2D matrix surface depends on substrate stiffness (Engler et al., 2006). MSCs cultured in hydrogels with stiffness of lower (0.1$1 \mathrm{kPa})$, intermediate $(8-17 \mathrm{kPa})$ or higher ranges $(34 \mathrm{kPa})$ can differentiate into neural, myogenic or osteogenic phenotypes, respectively. However, the microenvironment provided to the cells in $3 \mathrm{D}$ culture differs from that in the traditional 2D system (Baker and Chen, 2012). Osteogenic differentiation of murine MSCs is enhanced in RGD modified alginate, agarose and PEG diacrylate (PEGDA) with intermediate stiffness (11-30 $\mathrm{kPa}$ ) (Huebsch et al., 2010) (Figure 1A). Influence of stiffness on chondrogenic, vascular and neural differentiation has also been studied (Banerjee et al., 2009; Bian et al., 2013; Mahadevaiah et al., 2015). For instance, to investigate the influence of stiffness on the maintaining of chondrocyte phenotype, GelMA hydrogels with different stiffness but the same RGD density are prepared by changing the degree of methacryloyl substitution while using the same GelMA concentration. Bovine articular chondrocytes are encapsulated and cultured in the GelMA hydrogel with low, medium and high stiffness. The chondrocytes encapsulated in 
TABLE 2 | Physical properties of hydrogels and their performance as TE scaffolds.

\begin{tabular}{|c|c|c|c|c|}
\hline $\begin{array}{l}\text { Physical } \\
\text { properties }\end{array}$ & Materials & Approaches & Applications and performance & References \\
\hline \multirow[t]{2}{*}{$\begin{array}{l}\text { Mechanical } \\
\text { strength }\end{array}$} & GelMA & $\begin{array}{l}\text { Chitin nanofibers, Nanoparticles } \\
\text { blending }\end{array}$ & $\begin{array}{l}\text { Strain-to-failure increased } 200 \% \text { after chitin } \\
\text { nanofiber assembly; stiffness of collagen-based } \\
\text { hydrogel increased } 10 \text {-fold after addition of } \\
\text { functionalized nanoparticles. }\end{array}$ & $\begin{array}{l}\text { Jaiswal et al., 2015; } \\
\text { Hassanzadeh et al., } \\
2016\end{array}$ \\
\hline & PAMPS/PDMAAm & Double network & $\begin{array}{l}\text { High strength PAMPS/PDMAAm gel could induce } \\
\text { spontaneous hyaline cartilage regeneration in the } \\
\text { osteochondral defect. }\end{array}$ & $\begin{array}{l}\text { Yasuda et al., 2009; } \\
\text { Fukui et al., } 2014\end{array}$ \\
\hline \multirow[t]{2}{*}{ Stiffness } & $\begin{array}{l}\text { RGD modified alginate, } \\
\text { agarose, and PEGDA }\end{array}$ & $\begin{array}{l}\text { Tuning of } \mathrm{Ca}^{2+} \text { or polymer } \\
\text { concentration }\end{array}$ & $\begin{array}{l}\text { Intermediate stiffness promoted the osteogenic } \\
\text { differentiation of murine MSCs. }\end{array}$ & Huebsch et al., 2010 \\
\hline & $\begin{array}{l}\text { Four-arm } \\
\text { maleimide-functionalized }\end{array}$ & $\begin{array}{l}\text { By using different PEG } \\
\text { concentration }\end{array}$ & $\begin{array}{l}\text { The proliferation, self-renewal and vascular } \\
\text { differentiation of stem cells were enhanced in lower }\end{array}$ & $\begin{array}{l}\text { Mahadevaiah et al., } \\
2015\end{array}$ \\
\hline
\end{tabular}
maleimide-functionalized concentration $\quad$ differentiation of stem cells were enhanced in lower 2015 stiffness hydrogel.

thiol-functionalized PEG

MeHA Tuning of macromer concentration or UV exposure time

Gel-HPA

Altering macromer and/or $\mathrm{H}_{2} \mathrm{O}_{2}$ concentration

GelMA

Using the same macromer concentration with different methacryloyl substitution

\begin{tabular}{lll}
\hline $\begin{array}{l}\text { Stress } \\
\text { relaxation }\end{array}$ & RGD-alginate & $\begin{array}{l}\text { Tuning of stress-relaxation by } \\
\text { using alginate with different } \\
\text { molecular weight or PEG spacer } \\
\text { Same as above }\end{array}$ \\
HA, Collagen I & \\
& $\begin{array}{l}\text { Dynamic crosslinking of HA-ALD } \\
\text { and HA-BLD, combined with } \\
\text { collagen }\end{array}$ \\
\end{tabular}

Self-healing Glycol chitosan, Reversible Schiff-base reaction
benzaldehyde functioned PEG

Dynamic acylhydrazone bond and DA click covalent crosslinking

\section{Degradation GelMA}

Sulfated HA

HA functionalized with both maleimide and methacrylate

PEG-derivative
PEG-derivative
Collagenase degradable photocrosslinked gelatin hydrogel

Slowing the degradation of $\mathrm{HA}$ hydrogel by sulfated modification Thiol-ene crosslinking via MMP degradable crosslinker and photocrosslinking

Hydrogel crosslinked by PEG derivative containing nitrobenzyl ether moieties could be degradable by photo exposure.

Modification of ends of PEG with oligo (lactic acid) and acryloyl, hydrolysis of the ester bonds altered the degradation
Low stiffness of HA hydrogel promoted

Bian et al., 2013

chondrogenic differentiation of MSCs. Highly crosslinked HA hydrogel promoted hypertrophic conversion of encapsulated MSCs.

Medium stiffness showed superior stimulus for maintaining of chondrogenic phenotype, high stiffness promoted collagen type II gene expression.

High stiffness environment was beneficial for maintaining of chondrogenic gene expression.

Wang et al., 2014

Li et al., 2016

Fast stress relaxation promoted MSC spreading and Chaudhuri et al., 2016 osteogenic differentiation.

Slow relaxing environment restricted cell volume

Lee et al., 2017 expansion, up-regulated the gene related to matrix degradation and cell death.

Fast relaxation promoted cell spreading and focal L Lou et al., 2018 adhesion formation.

Tseng et al., 2015; Hsieh et al., 2017 and neural differentiation of neural stem cells, and enhanced capillary inducing capacity of vascular endothelial cells.

Increasing the viability, decreasing apoptosis of Lü et al., 2017 MSCs and promoting bone regeneration

Valvular interstitial cells had more spreading Benton et al., 2009 morphology in collagenase treated GelMA hydrogel than untreated hydrogel.

The low degradation was beneficial for chondrogenesis of MSCs.

Differentiation of MSC was directed by degradation-mediated cellular traction.

Khetan et al., 2013

MSC spreading was enhanced after

Kloxin et al., 2010 photodegradation.

The high degradation enhanced osteogenesis of

Peng et al., 2018 
A (i)
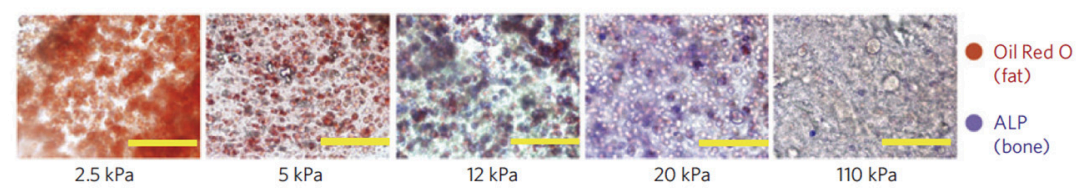

(ii)
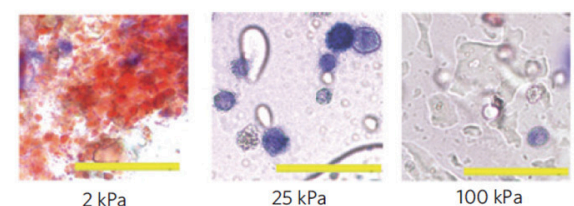

(iii)
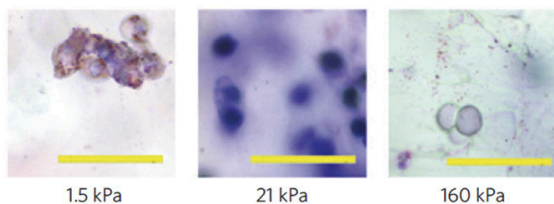

(iv)

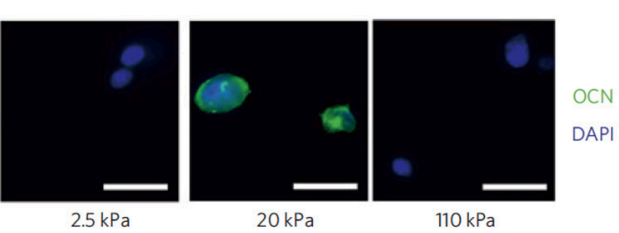

B (i)
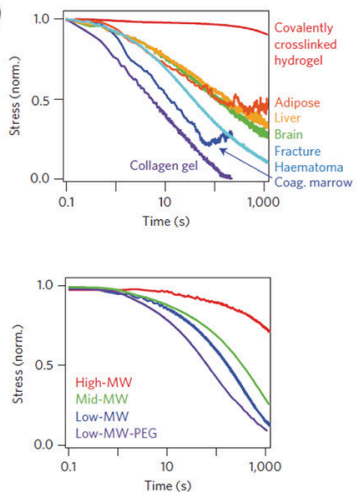

(ii)

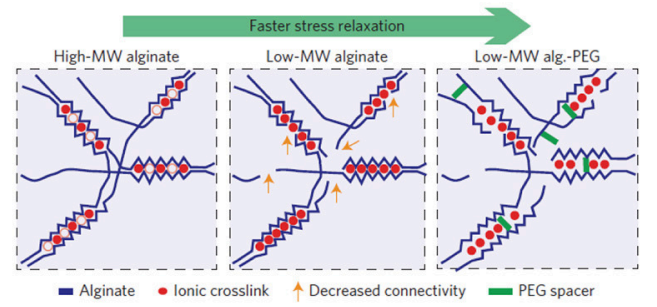

(iii)
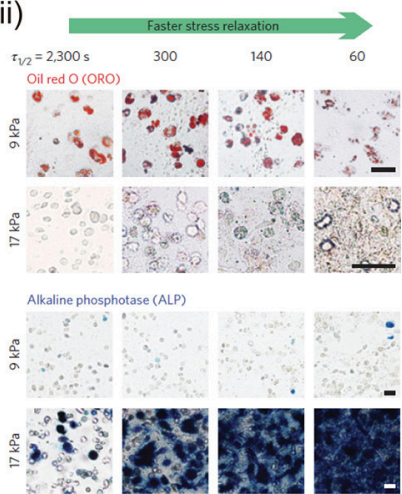

FIGURE 1 | Control of stiffness and stress relaxation of hydrogels and their influence on cell functions: (A) MSC differentiation affected by the stiffness of RGD-modified alginate (i), RGD-modified agarose (ii), and RGD-modified PEGDA (iii) hydrogels. Alkaline phosphatase (ALP) activity (fast blue; osteogenic biomarker, blue) and neutral lipid accumulation (oil red O; adipogenic biomarker, red) staining of MSCs after 1 week of culture. Osteocalcin (OCN, green) and nuclear counterstain 4',6-diamidino-2-phenylindole (DAPI, blue) staining in alginate hydrogel (iv). Scale bars: (i) $100 \mu \mathrm{m}$, (ii)-(iii) $50 \mu \mathrm{m}$ and (iv) $20 \mu \mathrm{m}$, respectively. Reproduced with the permission from Huebsch et al. (2010), Copyright @ 2010, Springer Nature. (B) Stress relaxation properties of living tissues and prepared hydrogels (i). Decreasing molecular weight (MW) of alginate and coupling PEG spacers both are predicted to increase the rate of stress relaxation (ii). MSCs cultured in hydrogels at indicated initial modulus and timescale of stress relaxation undergo adipogenic and osteogenic differentiation (Oil Red $\mathrm{O}$ staining and alkaline phosphatase staining) for 7 days (iii). Scale bars are $25 \mu \mathrm{m}$. Reproduced with the permission from Chaudhuri et al. (2016), Copyright ๑ 2016, Springer Nature.

high stiffness hydrogel exhibit round cell morphology and high chondrogenic gene expression, while chondrocytes cultured in low stiffness counterparts show elongated morphology and low chondrogenic gene expression (Li et al., 2016).

\section{Stress Relaxation}

Stress relaxation is another important mechanical property for hydrogels, which also is a common behavior of tissue matrix. It has been reported that ionic and covalent hydrogels both exhibit stress relaxation through uncoupling-reforming of crosslinks and migration of water, respectively (Zhao et al., 2010). Ionic hydrogels have faster stress relaxation and easier modulation than that of covalent hydrogels. Sodium alginate has been commonly used to form hydrogels with tunable stress relaxation. In a previous study, RGD modified alginate has been used to prepare soft but highly stress-relaxing substrate. Cells cultured in this substrate spread similarly to the cell on the surface of stiff elastic substrates (Chaudhuri et al., 2015). The stress relaxation of covalently crosslinked PAM hydrogel, physically crosslinked collagen hydrogel and living tissues like adipose, liver, brain and an initial fracture haematoma are compared by measuring the stress change when fixing the strain at 15\% (Chaudhuri et al., 2016). The results indicate that the stress relaxation of collagen hydrogel is faster than that of living tissues and PAM hydrogel, while that of PAM is slowest. RGD coupled alginate with different molecular weights and PEG spacers are used to prepare hydrogels with different stress relaxation properties independent of initial elastic modulus and matrix degradation. Fast stress relaxation enhances cell spreading, proliferation and osteogenic differentiation of stem cell through integrin-RGD binding and clustering (Figure 1B). Stress relaxation has also been demonstrated to have the capability to alter chondrocyte phenotype and matrix deposition via modulating cell volume expansion (Lee et al., 2017). Slow relaxing environment restricts 
cell volume, leading to interleukin-1 $\beta$ secretion increase, which in turn up-regulates the genes related to matrix degradation and cell death. To fully mimic the mechanical and structural cues of native ECM, HA crosslinked with dynamic covalent bonds and fibrillar collagen type I are used to prepare IPN hydrogel with tunable stress relaxation (Lou et al., 2018). Cell spreading, fiber remodeling and focal adhesion formation are enhanced in the faster relaxation hydrogels.

\section{Self-Healing}

Self-healing hydrogel is able to intrinsically and automatically heal the breaks, making itself back to original shape and mechanical property. This property is directly based on the reversible or dynamic crosslinking chemistry (Taylor and in het Panhuis, 2016). One of the representative self-healing hydrogels is prepared by glycol chitosan and benzaldehyde functionalized PEG via Schiff-base reaction (Tseng et al., 2015). The proliferation rate and differentiation tendency of neurosphere-like progenitors cultured in this self-healing hydrogel are enhanced (Figure 2A). Thrombin crosslinked fibrinogen can build a 3D network structure, which is used to prepare IPN structure after mixing with the above-mentioned chitosan-PEG hydrogel (Hsieh et al., 2017). This hydrogel encapsulated with vascular endothelial cells shows excellent self-healing and capillary-inducing capacity. Injection of this hydrogel promotes angiogenesis in zebrafish and mice. Dynamic acylhydrazone bond and Diels-Alder click covalent crosslinking are combined to prepare self-healing hydrogels with desirable mechanical property (Lü et al., 2017). These hydrogels increase the viability, reduces apoptosis of MSCs, and enhances bone regeneration in cranial bone defects. Guest-host crosslinking has also been used to prepare self-healing hydrogels. Cyclodextrin conjugated in one polymer backbone can work as the host to engulf hydrophobic moieties of another polymer chain to achieve self-healing. This self-healing property can further be selectively improved when the stimuli-responsive moiety, such as polyacrylamide-ferrocene with a reversible hydrophobic-charge transition at reduced/oxidized state, is included in the above hydrogels (Nakahata et al., 2011).

\section{Degradation}

Covalently crosslinked hydrogels can undergo degradation through ester hydrolysis, enzymatic hydrolysis or photolytic cleavage of the polymer chains (Kharkar et al., 2013). Based on these mechanisms, hydrogels could be designed with good biodegradability and desirable degradation rate, working as temporary supports and being degraded and replaced by the regenerating tissues gradually (Bryant et al., 2004). For example, the photocrosslinkable PVA/PEG hybrid hydrogels with controlled degradation profiles have been used for cartilage TE.
A (i)

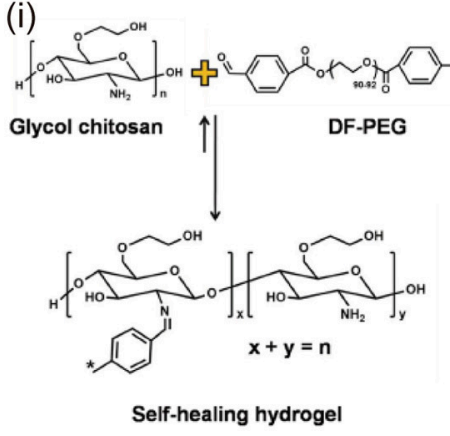

(ii)

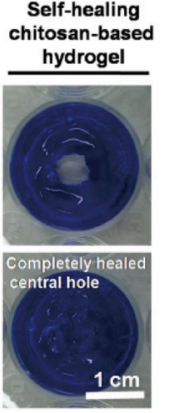

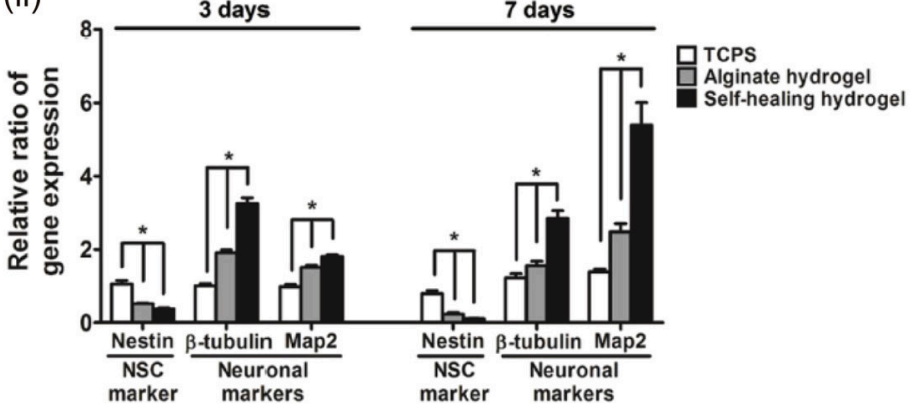

B (i)

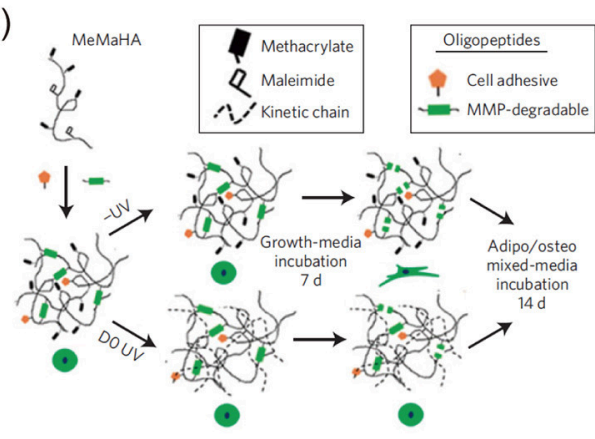

(ii)

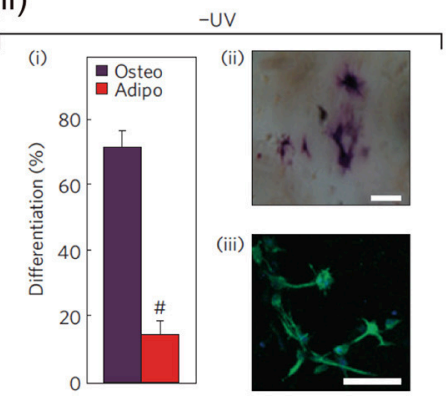

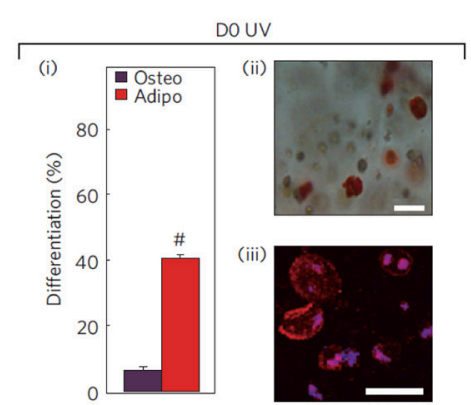

FIGURE 2 | The influence of hydrogel self-healing and degradation on cell functions: (A) Self-healing hydrogel formed by crosslinking of benzaldehydes at both ends of difunctionalized PEG (DF-PEG) with glycol chitosan (i). The expressions of neuronal-related genes (nestin, $\beta$-tubulin, and Map2) of cells after 3 and 7 days of culture in $3 D$ gels, ${ }^{*} p<0.05$ (ii). Reproduced with the permission from Tseng et al. (2015), Copyright ( $) 2013$, John Wiley and Sons. (B) (i) Schematic of sequential crosslinking of MeMaHA using a primary addition and secondary radical polymerization to create -UV and DO UV hydrogels. (ii) Percentage of hMSCs toward osteogenic or adipogenic differentiation in -UV or D0 UV hydrogels (\#p < 0:005, $t$-test). Reproduced with the permission from Khetan et al. (2013), Copyright $\odot$ ( 2013, Springer Nature. 
The degradation time can be tuned from less than 1 to 34 days by altering the ratio of PVA to PEG. The results show that the DNA and GAG contents increase with culture time and the neocartilaginous tissue at 6 weeks is homogeneously distributed in the PVA/PEG hydrogel with the ratio of 1:3, indicating the importance of degradation for TE (Martens et al., 2003). When implanted in vivo, HA-based hydrogel often shows too fast degradation to meet the requirement for cartilage tissue repair. To solve this limitation, sulfate groups are conjugated to HA to decelerate the hyaluronidase degradation rate. Sulfated HA displays slow degradation and enhances protein binding ability, promoting chondrogenesis of hMSCs with reduced hypertrophy (Feng et al., 2017).

Degradation of the hydrogel is a chemical process, but it can work as a dynamically physical stimulus to affect cell behaviors and functions for cell-matrix interaction, such as cell spreading, migration, proliferation, and differentiation, to further mimic the native ECM and improve the tissue regeneration. For example, photo-responsive hydrogels can be prepared from PEG derivatives containing nitrobenzyl ether photolabile moieties. When human mesenchymal stem cells (hMSCs) are cultured in the photodegradable hydrogel, cell spreading is enhanced after light exposure (Kloxin et al., 2010). Degradation of hydrogel is always accompanied with decrease of stiffness, making it complicated to discriminate the influences of degradation and stiffness. To decouple the influence from mechanical property of degradable hydrogels, hydrogels are designed to degrade while their mechanical properties remain unchanged. For example, HA functionalized with both maleimide and methacrylate is used to prepare hydrogels by thiol-ene crosslinking via MMP degradable crosslinker and photo-initiated crosslinking of the methacrylate. The MMP-cleavable peptide crosslinker permits cell-mediated degradation. The photo-initiated crosslinking can dynamically control the secondary crosslinking at the very beginning or after a period of cultivation. The stiffness of hydrogels with or without UV exposure is controlled at the same level by changing the molecular weight of HA macromers. When hMSCs are cultured in the tuned hydrogels, they exhibit different osteogenic and adipogenic differentiation. The results indicate that hMSCs differentiation is directed by degradation-mediated cellular traction, independent of the matrix mechanics. (Khetan et al., 2013) (Figure 2B).

\section{CONTROL OF CHEMICAL PROPERTIES}

The composition of hydrogels can highly affect the cell behaviors including viability, adhesion, spreading, proliferation, and differentiation (Ruoslahti and Pierschbacher, 1987). Hydrogel composition can be controlled by choosing different precursors and preparation methods. The methods used to tune chemical properties of functional hydrogels are summarized in Table 3.

Cell adhesion ligand is a crucial biochemical component in ECM, because many types of cells have to adhere to their microenvironment through cell surface integrin to perform the relative functions and maintain their viability (Huettner et al., 2018). Naturally derived proteins, like collagen and gelatin, retain many cell adhesion ligands. However, polysaccharidebased natural materials and synthetic polymers are lack of these ligands. Hence, bioactive peptide modification has been used to improve the biochemical property of non-adhesive hydrogels. RGD peptide, as one of the potent adhesion ligands, plays an important role on cell adhesion and other functions. To study the impact of dynamic presentation of RGD in matrix on cell functions, a light-responsive PEGDA hydrogel is synthesized, in which a protecting group is used to temporally and spatially control the RGD presentation by transdermal light exposure (Figure 3A). PEGDA hydrogels

TABLE 3 | Control of chemical properties of hydrogels for TE applications.

\begin{tabular}{|c|c|c|c|}
\hline $\begin{array}{l}\text { Original } \\
\text { hydrogels }\end{array}$ & Approaches & Applications and Performance & References \\
\hline $\begin{array}{l}\text { HA, alginate, } \\
\text { chitosan, and PEG }\end{array}$ & $\begin{array}{l}\text { Modifying hydrogel precursors with } \\
\text { RGD peptides }\end{array}$ & $\begin{array}{l}\text { Promoted cell adhesion and viability, enhanced cell } \\
\text { proliferation and differentiation }\end{array}$ & $\begin{array}{l}\text { Lee et al., 2015; Kim et al., } \\
\text { 2016; Long et al., 2017; Sun } \\
\text { et al., } 2017\end{array}$ \\
\hline Polyacrylamide & Hybridization with GelMA & Improved biocompatibility of synthetic hydrogels & Han et al., 2017 \\
\hline PEG & Hybridization with HA & $\begin{array}{l}\text { Increased chondrocyte number and SGAG and } \\
\text { collagen production }\end{array}$ & $\begin{array}{l}\text { Skaalure et al., 2014; Fu et al., } \\
2017\end{array}$ \\
\hline PEG & $\begin{array}{l}\text { Covalently tethered transforming } \\
\text { growth factor-beta } 1 \text { (TGF- } \beta 1 \text { ) to PEG } \\
\text { hydrogel through thiol-ene reaction }\end{array}$ & $\begin{array}{l}\text { Increased chondrogenic matrix deposition by } \\
\text { immobilization of TGF- } \beta 1\end{array}$ & $\begin{array}{l}\text { Sridhar et al., 2014; Mao et al., } \\
2017\end{array}$ \\
\hline GelMA & Hybridization with nanosilicates & $\begin{array}{l}\text { Promoted osteogenic differentiation of } \\
\text { preosteoblasts in a growth-factor-free } \\
\text { microenvironment }\end{array}$ & Xavier et al., 2015 \\
\hline $\begin{array}{l}\text { GelMA } \\
\text { Collagen/Alginate }\end{array}$ & $\begin{array}{l}\text { Hybridization with multiwalled CNTs } \\
\text { Gold nanorod }\end{array}$ & $\begin{array}{l}\text { Improved cell adhesion and maturation; enhanced } \\
\text { cardiac tissue regeneration, exhibiting strong } \\
\text { spontaneous and stimulated synchronous beating }\end{array}$ & $\begin{array}{l}\text { Shin et al., 2013; Navaei et al., } \\
\text { 2016a; Izadifar et al., } 2018\end{array}$ \\
\hline Polyacrylamide & Hybridization with graphene oxide & $\begin{array}{l}\text { Enhanced proliferation and myogenic differentiation } \\
\text { of } \mathrm{C} 2 \mathrm{C} 12 \text { cells, and combining electrical stimulation } \\
\text { further enhanced myogenic gene expression }\end{array}$ & Jo et al., 2017 \\
\hline
\end{tabular}


with RGD peptides and light-induced uncaged RGD peptides support high number of adherent cells. On the other hand, PEGDA hydrogels without RGD modifications or with caged RGD support few adherent cells and the cells have round morphology. Besides, it has been reported that RGD peptides can be introduced to polymers, such as HA (Lee et al., 2015), alginate (Sun et al., 2017), chitosan (Kim et al., 2016), and PEG (Long et al., 2017), by chemical binding to fabricated bioactive hydrogels. These functionalized hydrogels show improved biological properties to promote cell adhesion, spreading, proliferation, and differentiation. For instance, RGD peptides promote the survival of MSCs in PEG hydrogels and induce the chondrogenic differentiation (Salinas and Anseth, 2008). RGD ligands in hydrogels increase the chondrogenic gene expression when the hydrogel matrices are loaded with dynamic mechanical force (Steinmetz and Bryant, 2011). Moreover, RGD density affects the redifferentiation of chondrocytes (Schuh et al., 2012).

Hybridization with natural polymers is another facile way to tune the biochemical property of hydrogels, which can change the composition of hydrogels in favor of promotion of cell function and TE. For example, GelMA is used to hybridize with PAM to prepare a photopolymerized hydrogel for cartilage tissue regeneration. Cells cultured in the hybrid hydrogel exhibit higher viability and proliferation rate than those cultured in pure PAM hydrogel (Han et al., 2017). What's more, HA/PEG hybrid hydrogel prepared via the SPAAC crosslinking shows excellent biocompatibility (Fu et al., 2017), which may be due to the fact that HA can bond to some receptors on cell membrane to affect both chondrocyte survival pathway and apoptotic pathway (Knudson and Knudson, 2004).

Besides hybridization with natural polymers or modification with biological moieties to improve the biochemical properties of hydrogels for TE, loading of growth factors and nanoparticles have been frequently adapted to improve hydrogel functions. Growth factors play important roles in cell growth, cell function determination, tissue regeneration, and organ development (Parker et al., 2016; Yan et al., 2018). Therefore, immobilization of growth factors in hydrogels will significantly improve the functionality of hydrogels. There are two strategies for

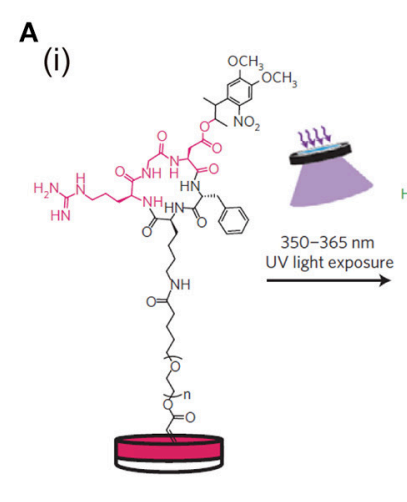

$\mathbf{B}_{(\mathrm{i})}$
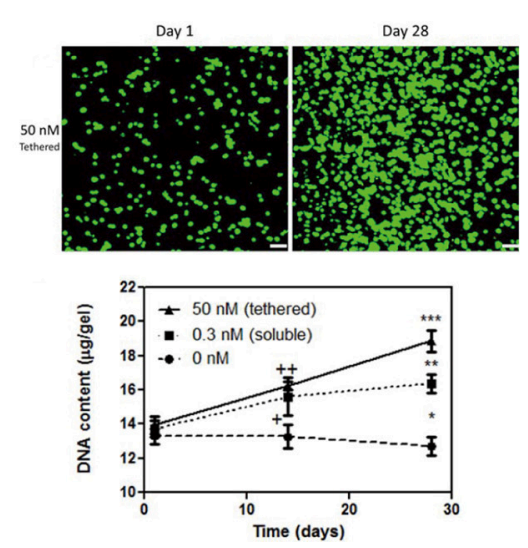

(ii)

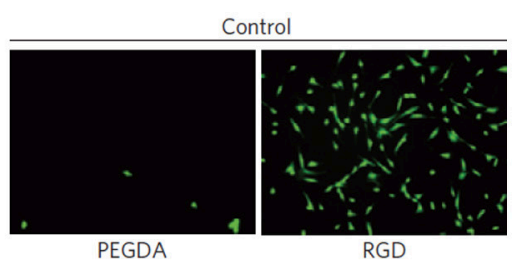

Caged RGD

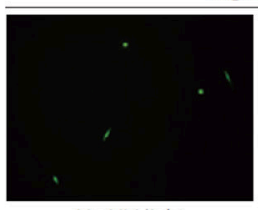

No UV light

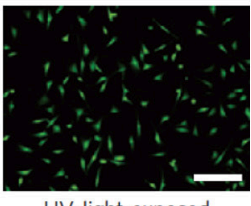

(ii)

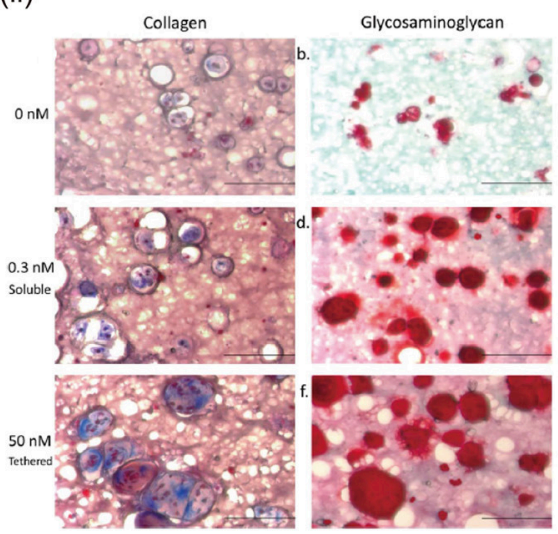

FIGURE 3 | The effects of RGD peptides and growth factors in hydrogels on cell functions: (A) Schematic representation of the activation of caged RGD peptides in PEGDA hydrogels under light exposure (i). Cell adhesion and spreading can be enhanced after culture in hydrogels with RGD peptides and UV-light-exposed caged RGD peptides (ii). Reproduced with the permission from Lee et al. (2015), Copyright $\odot 2015$, Springer Nature. (B) ECM production of chondrocytes is enhanced after culture in PEG hydrogels with covalently tethered TGF- $\beta$. DNA content of chondrocytes exposed to $50 \mathrm{nM}$ tethered TGF- $\beta$ is the highest (i). Chondrogenic matrix (collagen and glycosaminoglycan) deposition is enhanced when exposing to TGF- $\beta$. The matrix produced in $50 \mathrm{nM}$ (tethered) group is higher than that in $0.3 \mathrm{nM}$ (soluble) group (ii). Reproduced with the permission from Sridhar et al. (2014), Copyright $\odot$ 2014, John Wiley and Sons. 
immobilizing growth factors in hydrogels, namely physical, and chemical immobilization (Nguyen and Alsberg, 2014). Heparin can bind many types of growth factors through the strong electrostatic interactions. The immobilization of fibroblast growth factor-2 and vascular endothelial growth factor in heparin-modified PEG hydrogels has been shown to boost angiogenesis (Zieris et al., 2010). Compared with physical immobilization, chemical immobilization can further improve the stability, prolong the release of growth factors, and reduce the required amount. For example, transforming growth factorbeta 1 (TGF- $\beta 1$ ) is covalently tethered to PEG hydrogel through thiol-ene reaction (Sridhar et al., 2014; Mao et al., 2017). Chondrocytes cultured in PEG hydrogel immobilized with TGF- $\beta 1$ show higher DNA content and chondrogenic matrix production than the cells cultured in PEG hydrogel with soluble TGF- $\beta 1$ (Figure 3B).

A variety of nanoparticles have also been incorporated into different kinds of natural or synthetic polymer networks to prepare nanocomposite hydrogels for TE. The incorporation of nanoparticles can provide not only higher mechanical properties, but also the possibility to tune biochemical characteristics of the 3D network. For examples, nanosilicates are incorporated into GelMA hydrogels to obtain a bioactive nanocomposite (Xavier et al., 2015). Not only the mechanical strength of the hydrogel is enhanced, osteogenic differentiation of preosteoblasts is also promoted (Figure 4). In another study, nanosized hydroxyapatite is incorporated into a PEG hydrogel aiming to produce highly tough matrix for bone TE. After incorporation, the morphologies of these hydrogels show highly interconnected porous structures. What's more, the presence of hydroxyapatite nanoparticles can provide osteoblast cells adhesion and bioactive attachment sites compared with pure PEG hydrogels (Gaharwar et al., 2011). For cardiac tissue regeneration, conductive nanoparticles like carbon nanotubes are added into GelMA hydrogels, resulting in improved cell adhesion and maturation (Shin et al., 2013). The percentage of cell retention and viability on carbon nanotubes nanocomposite GelMA hydrogel is higher than those on pristine GelMA. The mature cell/hydrogel sheet with very good electrophysiological and mechanical properties exhibits strong spontaneous and stimulated synchronous beating.

\section{STRUCTURAL CONTROL OF HYDROGELS}

Microstructure is another critical factor to affect cell activities and functions because the optimized architecture of engineered tissue has the function to organize multiple cell types for TE (Stevens et al., 2013). Hydrogels with microarchitectures are briefly classified into microporous, channel-bearing, double-ring, multilayered, and hierarchically structured ones. The structure types of functional hydrogels and their influence on cell functions and tissue regeneration are summarized in Table 4.

\section{Microporous Hydrogels}

The structure of bulk hydrogels is dense polymers with absorbed water and nano-sized pores within the network (Hoffman, 2012), in which, the nano-sized pores are too small to promote cell migration, proliferation and ECM diffusion. Thereby,
A
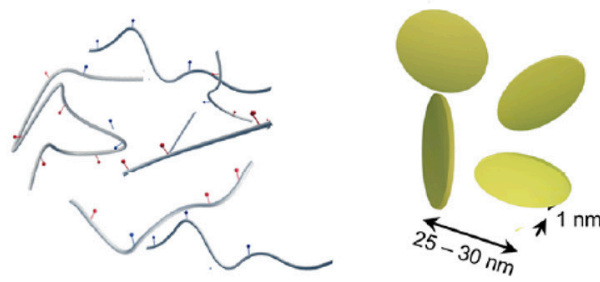

GelMA

B

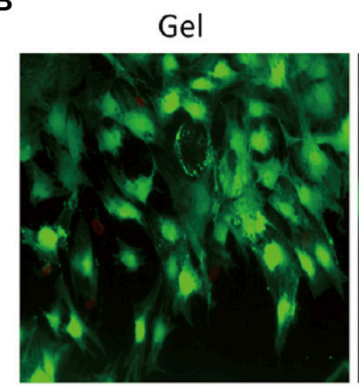

Nanosilicates

$2 \%$ Nanosilicates

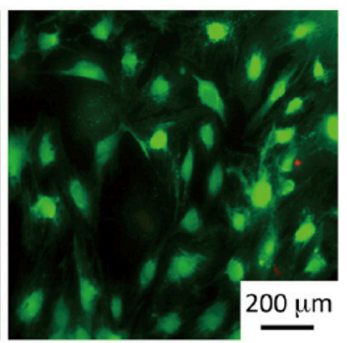

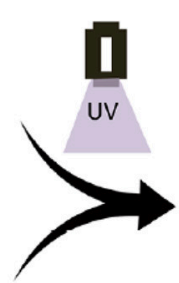

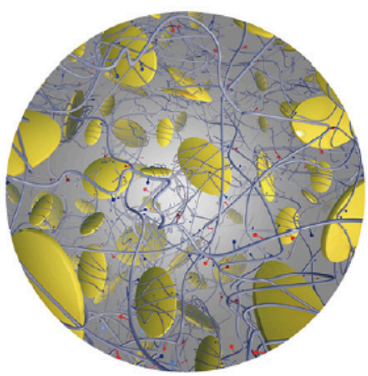

Nanocomposite Hydrogels

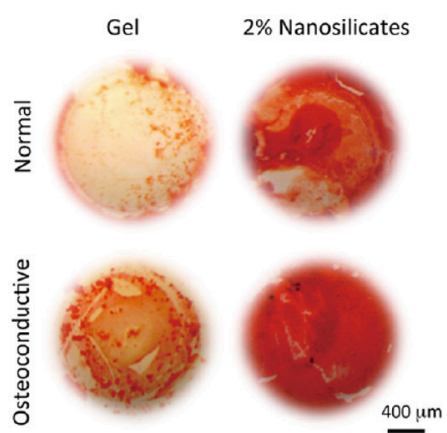

FIGURE 4 | Schematic illustration of fabrication of nanocomposite hydrogels from GelMA and nanosilicates by photocrosslinking (A). Nanosilicate-loaded gelatin hydrogels can support cell adhesion and spreading (live/dead staining) and enhance inorganic calcium deposition in normal and osteoconductive media (Alizarin Red S staining) (B). Reproduced with the permission from Xavier et al. (2015), Copyright @ 2015, American Chemical Society. 
TABLE 4 | Structural control of hydrogels and TE applications.

\begin{tabular}{|c|c|c|c|c|}
\hline $\begin{array}{l}\text { Structural } \\
\text { hydrogels }\end{array}$ & Materials & Approaches & Applications and Performance & References \\
\hline \multirow[t]{3}{*}{$\begin{array}{l}\text { Porous } \\
\text { structure }\end{array}$} & $\begin{array}{l}\text { Alginate } \\
\text { HA }\end{array}$ & $\begin{array}{l}\text { Mixing with gelatin particles prepared by } \\
\text { water/oil emulsion }\end{array}$ & $\begin{array}{l}\text { Chondrogenic matrix secretion and gene } \\
\text { expression were improved in alginate and } \\
\text { HA porous hydrogels. }\end{array}$ & $\begin{array}{l}\text { Fan and Wang, } 2015 ; \\
\text { Leong et al., } 2016\end{array}$ \\
\hline & GelMA & $\begin{array}{l}\text { Mixing with gelatin cubes prepared by } \\
\text { mesh-cutting }\end{array}$ & $\begin{array}{l}\text { Chondrocytes migration and proliferation } \\
\text { were enhanced in porous structures. }\end{array}$ & Li et al., 2017a \\
\hline & GelMA & $\begin{array}{l}\text { Gelatin, alginate, and HA porogens } \\
\text { prepared by water/oil emulsion can be } \\
\text { degraded to specific stimuli including } \\
\text { temperature, chelating and enzymatic } \\
\text { digestion, respectively. }\end{array}$ & $\begin{array}{l}\text { Increased cell proliferation and spreading, } \\
\text { and enhanced type II and X collagen } \\
\text { production happened in the hydrogel with } \\
\text { dynamic pore formation }\end{array}$ & Han et al., 2013 \\
\hline \multirow[t]{3}{*}{$\begin{array}{l}\text { Channel } \\
\text { structure }\end{array}$} & $\begin{array}{l}\text { 2-hydroxyethyl } \\
\text { methacrylate, agarose } \\
\text { or GelMA }\end{array}$ & Embedding PVA sacrificial templates & $\begin{array}{l}\text { High cell viability in bulk hydrogel was } \\
\text { achieved by this channel structures. }\end{array}$ & Tocchio et al., 2015 \\
\hline & Gelatin & $\begin{array}{l}\text { Embedding and dissolving solvent-spun } \\
\text { PNIPAM microfibers }\end{array}$ & & Lee et al., 2016 \\
\hline & $\begin{array}{l}\text { Agarose/alginate/PEG/ } \\
\text { Fibrin/Matrigel }\end{array}$ & $\begin{array}{l}\text { Carbohydrate-glass fibers were 3D printed } \\
\text { and removed after surround hydrogel } \\
\text { formation. }\end{array}$ & $\begin{array}{l}\text { Good biocompatibility and enhanced } \\
\text { nutrition diffusion. }\end{array}$ & Miller et al., 2012 \\
\hline $\begin{array}{l}\text { Double-ring } \\
\text { structure }\end{array}$ & $\begin{array}{l}\text { GelMA and } \\
\text { hydroxyapatite }\end{array}$ & $\begin{array}{l}\text { Osteon-like concentric double-ring } \\
\text { structure was prepared via } \\
\text { photolithography and self-assembly. }\end{array}$ & $\begin{array}{l}\text { HUVECs and MG63s were encapsulated } \\
\text { in the inner and outer ring, working as } \\
\text { blood vessel tubule and bone, respectively. }\end{array}$ & $\begin{array}{l}\text { Zuo et al., 2015; Wei } \\
\text { et al., } 2017\end{array}$ \\
\hline \multirow[t]{3}{*}{$\begin{array}{l}\text { Bilayered } \\
\text { structure }\end{array}$} & $\begin{array}{l}\text { Transglutaminase } \\
\text { factor XIII crosslinked } \\
\text { PEG hydrogels }\end{array}$ & $\begin{array}{l}\text { Chondrocytes and MSCs were } \\
\text { encapsulated in different hydrogel layers } \\
\text { functionalized with TGF- } \beta 3 \text { or BMP- } 2 \text {. }\end{array}$ & $\begin{array}{l}\text { Endochondral bone or stable cartilage can } \\
\text { be developed at an ectopic site without } \\
\text { the need of a predifferentiation process } \\
\text { in vitro. }\end{array}$ & Stüdle et al., 2018 \\
\hline & Agarose & $\begin{array}{l}\text { Chondrocytes and MSCs were } \\
\text { encapsulated in the top and bottom layer } \\
\text { agarose hydrogel for osteochondral TE. }\end{array}$ & $\begin{array}{l}\text { Coculture of chondrocytes and MSCs in } \\
\text { different environment showed potential for } \\
\text { osteochondral TE. }\end{array}$ & Sheehy et al., 2013 \\
\hline & PEG-derivative & $\begin{array}{l}\text { Top layer with low RGD concentration and } \\
\text { soft stiffness was designed for } \\
\text { chondrogenesis of MSC; bottom layer was } \\
\text { prepared with high RGD concentration and } \\
\text { high stiffness for osteogenesis of MSC. }\end{array}$ & $\begin{array}{l}\text { Spatial presentation of physiochemical } \\
\text { cues combined with dynamic mechanical } \\
\text { stimulation could regulate the } \\
\text { differentiation of MSCs. }\end{array}$ & Steinmetz et al., 2015 \\
\hline \multirow[t]{2}{*}{$\begin{array}{l}\text { Hierarchical } \\
\text { structure }\end{array}$} & PEG-derivative & $\begin{array}{l}\text { Hierarchical vessels were fabricated by } \\
\text { multiphoton lithography. }\end{array}$ & $\begin{array}{l}\text { Human bone marrow-derived hS5 stromal } \\
\text { cells exhibited high viability for a long } \\
\text { culture period. }\end{array}$ & Arakawa et al., 2017 \\
\hline & POMaC and collagen & $\begin{array}{l}\text { POMaC made scaffold with nanopores } \\
\text { and micro-holes was prepared by using } \\
\text { 3D stamping technique. }\end{array}$ & $\begin{array}{l}\text { The incorporation of nanopores and } \\
\text { micro-holes enhanced permeability, and } \\
\text { permits intercellular crosstalk and } \\
\text { extravasation. }\end{array}$ & Zhang et al., 2016 \\
\hline
\end{tabular}

microporous structures have been proposed. The effects of different pore structures and pore size ranges have been studied for cell culture and TE (Zhang et al., 2014; Chen et al., 2016). Various technologies including solvent casting, particle leaching, freeze-drying, and gas foaming can be used to adjust hydrogel porosity (Annabi et al., 2010). Among them, stimuli-responsive porogens, such as gelatin, alginate and HA, are used to create cell-laden hydrogels with tunable porosity. These porogens can be removed by specific stimuli including temperature, chelating, and enzymatic digestion, respectively (Han et al., 2013). Similarly, gelatin microspheres fabricated by water/oil emulsion are used to generate micropores in alginate (Leong et al., 2016) and HA (Fan and Wang, 2015) hydrogels. Plenty of micropores are left after gelatin microbeads are dissolved at $37^{\circ} \mathrm{C}$. Chondrocytes cultured in the porous hydrogels show high proliferation and ECM secretion. Gelatin microparticles have also been used to prepare microporous hydrogels for bone TE (Vo et al., 2016). The pore-forming gelatin microparticles can be used not only for generation of micropores, but also for introduction of living cells in the micropores. Cell-laden gelatin microcubes are prepared by a mesh-cutting method and used to prepare microporous hydrogels with promotive capacity of cell proliferation ( $\mathrm{Li}$ et al., 2017a). Chondrocytes cultured in the microporous hydrogels show high proliferation and cells prefer to migrate into the microporous cavities (Figure 5A). 


\section{Channel-Bearing Hydrogels}

Cells must reside with $100-200 \mu \mathrm{m}$ from adjacent capillary blood vessels to remain viable or else they will undergo necrosis due to insufficient oxygenation and nutrition diffusion (Carmeliet and Jain, 2000). Therefore, hydrogels with micro-channels are highly needed to vascularize artificial tissue or study cell behaviors in a vascular structure, in particular for the regeneration of large and complex tissues and organs. Multiple strategies and techniques have been developed for preparation of channel-bearing hydrogels for TE applications.

PVA-based sacrificial templates are fabricated into branched fluidic architectures by casting (Tocchio et al., 2015). The architecture obtained after washing exhibits promoted regeneration of hierarchically branched endothelium and high cell viability inside bulk hydrogels formed by 2hydroxyethyl methacrylate, agarose or GelMA. To prepare a complex capillary-like micro-channel vascular structure, solvent-spun PNIPAM microfibers are fabricated and used as temperature-responsive templates (Lee et al., 2016). The PNIPAM microfibers are spun and maintained at a temperature above $32^{\circ} \mathrm{C}$. Cell-suspended gelatin precursor solution is kept at $37^{\circ} \mathrm{C}$ prior to embedding the templates. After complete gelation of the gelatin hydrogel, the PNIPAM microfibers are removed by immersion in cell culture medium at room temperature to generate the capillary-like micro-channel vascular structure. Cell viability is higher than $96 \%$ during 7 days of cultivation in the perfused micro-channel hydrogel. Carbohydrate-glass microfibers are printed to induce vascular architecture in bulk hydrogels, which can be removed by cell medium perfusion (Miller et al., 2012). The micro-channel hydrogels demonstrate good biocompatibility and enhanced nutrition diffusion. Combination of carbohydrate glass material with $3 \mathrm{D}$ printing provides independent control of vascular network

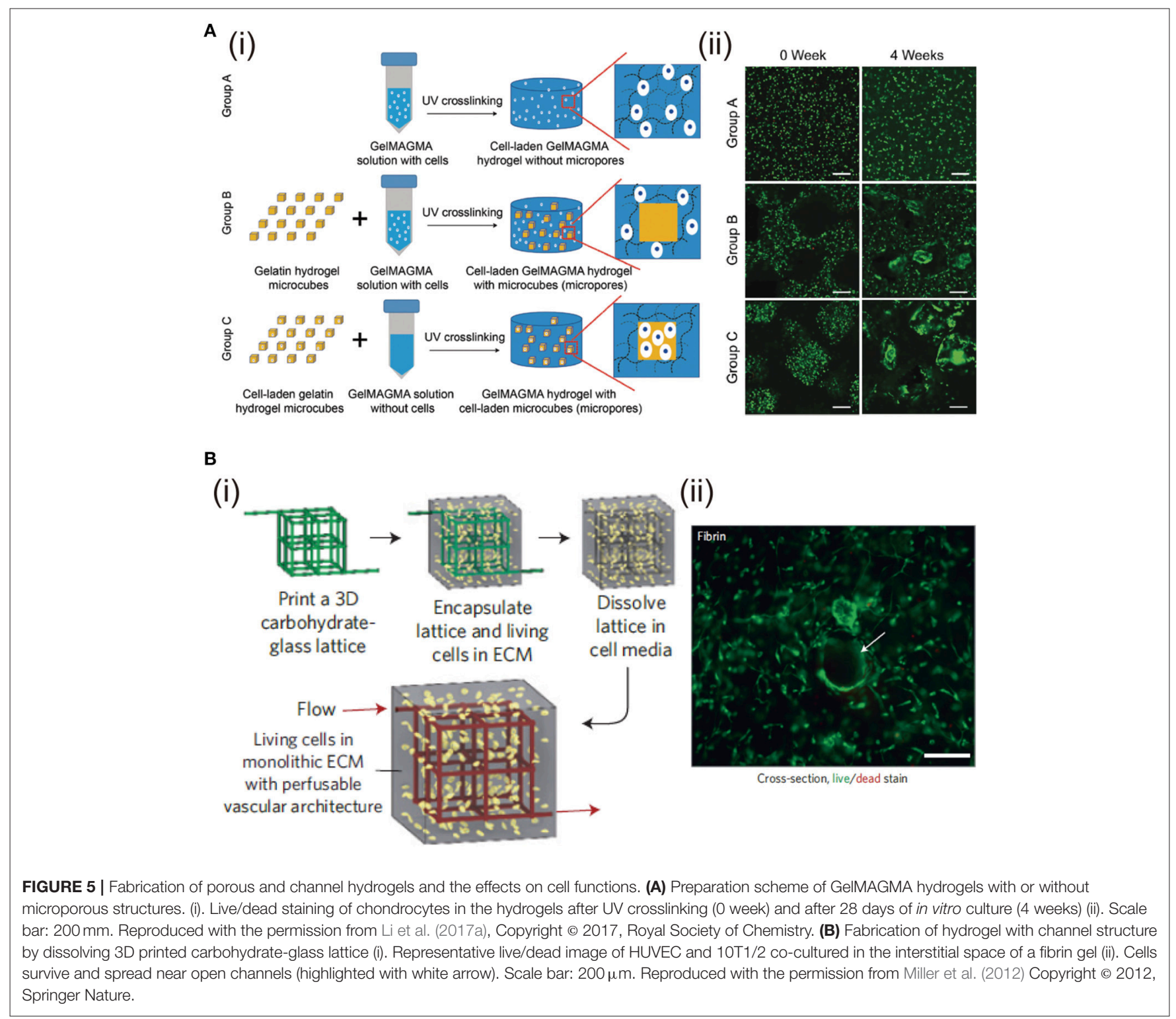


geometry, endothelialization, and extravascular tissue formation (Figure 5B).

\section{Double-Ring Structural Hydrogels}

Osteon-like concentric double-ring structure is prepared with hybrid hydrogels of GelMA and hydroxyapatite via photolithography technology and self-assembly (Zuo et al., 2015). Human umbilical endothelial cells (HUVECs) are encapsulated in the inner ring to mimic blood vessel tubules, while human osteoblast-like cells (MG63s) are located in the outer ring as bone part (Figure 6A). Expression of angiogenesisrelated and osteogenesis-related genes is promoted. Osteon-like fibers with HUVECs and MG63s separately encapsulated are constructed with the combination of photolithography and microfluidic chip techniques (Wei et al., 2017). RGD modified alginate precursor with photoreactive functionalization is used for the hydrogel preparation because the modified alginate possesses cell adhesive sites and $\mathrm{UV} / \mathrm{Ca}^{2+}$ crosslinkable properties. This not only satisfies cell proliferation but enhances the relative gene expression and protein secretion in the osteon-like architecture.

\section{Multilayered Hydrogels}

ECM composition and structure of cartilage and bone tissues have an obvious difference. The biochemical and biophysical microenvironments surrounding the cells in cartilage and bone are also different. To regenerate full-thickness articular cartilage defects, bilayered hydrogel architecture is designed.

A
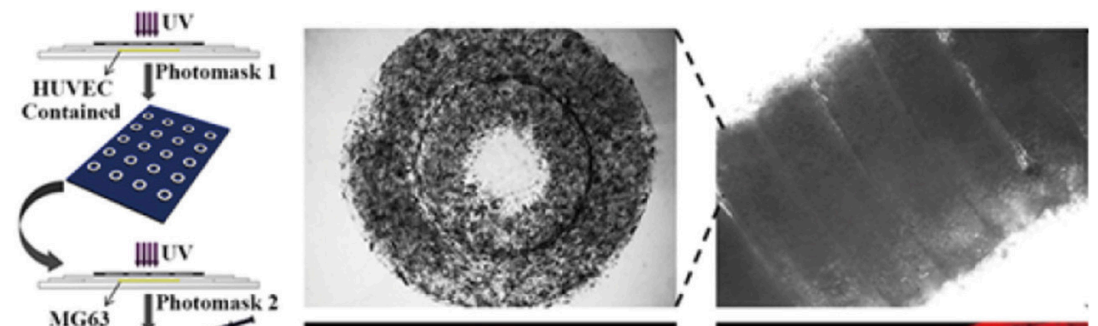

MG63 Tent
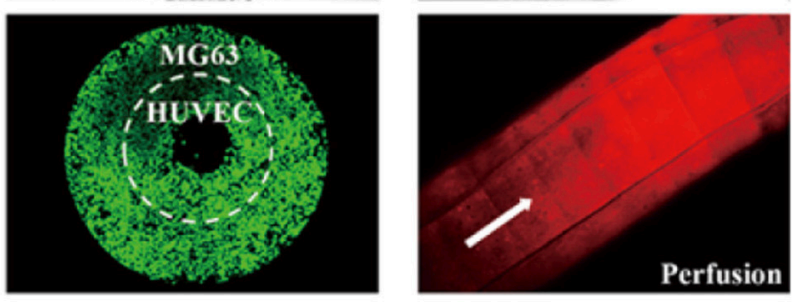

B

(i)

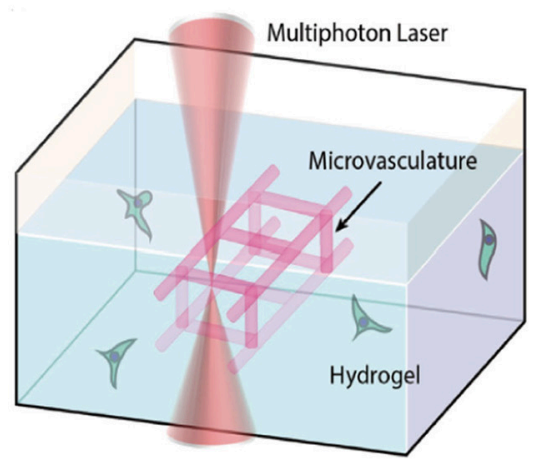

(ii)

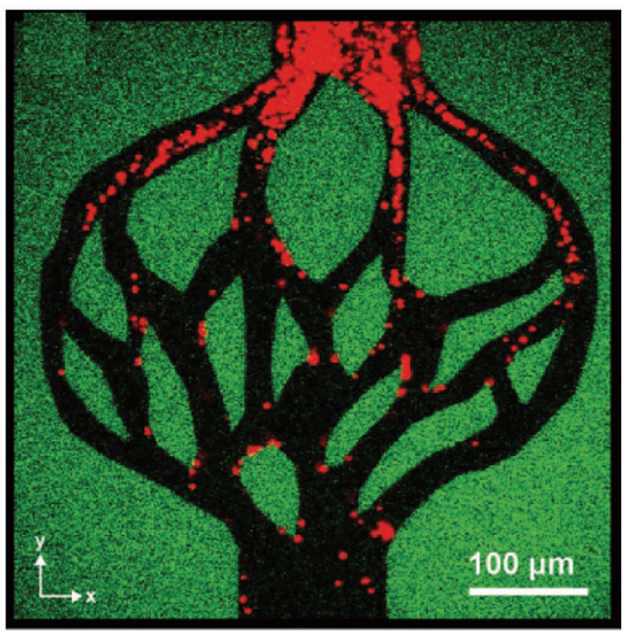

FIGURE 6 | Fabrication of double-ring and hierarchically structural hydrogels and the effects on cell functions. (A) Fabrication of hydrogels with osteon-like double-ring structure by photolithograph and self-assembly. Cell viability of MG63s and HUVECs encapsulated in the outer ring and inner ring of the osteon-like module. Reproduced with the permission from Zuo et al. (2015), Copyright ๑ 2015, American Chemical Society. (B) Degradation of the hydrogel through oNB photocleavage (i). Creation of hydrogels with hierarchical vascular structure by programmable photodegradation (ii). Reproduced with the permission from Arakawa et al. (2017), Copyright @ 2017, John Wiley and Sons. 
For example, bilayered agarose hydrogels are prepared for osteochondral tissue repair (Sheehy et al., 2013). The top hydrogel layer is encapsulated with chondrocytes, while the bottom layer is seeded with MSCs. After 49 days of in vitro cultivation, the top layer promotes production of cartilaginous ECM, while the hypertrophy of MSCs encapsulated in the bottom layer is decreased. The results indicate the bilayered structure has a great potential for spatially separated coculture of chondrocyte and MSCs and osteochondral tissue regeneration. Bilayered structure can also provide tunable biochemical and mechanical microenvironment for differentiation of MSCs. For example, the top hydrogel layer fabricated with low RGD concentration and soft matrix can promote chondrogenesis of MSCs, while, the bottom layer designed to have high RGD amount and stiff mechanical property can promote osteogenesis of MSCs (Steinmetz et al., 2015).

\section{Hierarchically Structured Hydrogels}

Hierarchical architecture exists in living tissues. For example, blood vessels possess many scales of size to adapt to tissue requirements. They include large arteries, smaller arterioles and smallest capillaries, which have the functions to permit large blood volume flow and support mass transport via diffusion (Michiels, 2003). The above mentioned methodologies for channel structures have limitations to introduce such hierarchical structures in cell-laden hydrogel constructs, especially for the size of diameter less than $150 \mu \mathrm{m}$ (Lee et al., 2014). Multiphoton lithography-assisted photoscission, as a cytocompatible fabrication strategy, is used to create hierarchical vessels spanning nearly all the size ranges in the human body (Arakawa et al., 2017) (Figure 6B). The hydrogel network is crosslinked by azide-alkyne cycloaddition between PEG tetrabicyclononyne and diazide-functionalized peptide. The photo degradation is based on the orthonitrobenzyl ester (oNB) moiety that undergoes photolysis upon exposure to pulsed near-infrared light (DeForest and Tirrell, 2015). Human bone marrow-derived hS5 stromal cells are encapsulated inside the hydrogel, followed by preparation of photodegradable vessels. The hS5 cells are viable during the whole culture period. This complex and hierarchical structures can maintain cell viability and functions, which is essential for regeneration of heterogeneous tissues. Furthermore, the hierarchical vascular structure is promising for investigation of endothelialization and blood-capillary interaction in the various environments.

3D stamping technique can also be used to prepare hydrogels with hierarchical structures. AngioChip with hierarchical vascular and porous architecture is prepared by this method
(Zhang et al., 2016). Nanopores and micro-holes are fabricated into the vascular walls to promote molecular exchange and cell migration. The permeability for large molecular $(70 \mathrm{kDa}$ TRITC-dextran) of AngioChip with micro-holes is more than 4 times higher than that of the counterparts without micro-holes. A confluent endothelium is exhibited on the microchannel surface and endothelial sprouts are observed through the micro-holes. Human embryonic stem cell-derived hepatocytes and hMSCs are encapsulated in a collagen matrix and seeded into the parenchymal space to engineer the AngioChip. Urea secretion per cell from this hierarchical construct is much higher than that of collagen sandwich control. Furthermore, this complex hierarchical structural AngioChip is also used for in vitro regeneration of cardiac tissue models and implantation for direct surgical anastomosis. Due to the complex and hierarchical architectures, cell viabilities and relative functions are enhanced.

\section{CONCLUSION AND OUTLOOKS}

Control of the structures and physiochemical properties of hydrogels is important for their utilization in TE. Cells first sense the signals from surrounding hydrogel matrix, which makes the physiochemical properties of hydrogel critical for cell functions. Various structures of hydrogels can further alter the microenvironments and provide the possibility of flow stimulus by micro-channel structure or co-culture microenvironment by spatially layered structures. A variety of preparation methods and functional hydrogels have been developed for TE of various tissues and organs. Despite of these progresses, hydrogels with further improved biochemical and biophysical properties, as well as biomimetic structures are deserved to be further studied. The explored hydrogels until now have some similar but not completely matched functions to the in vivo cell-surrounding microenvironments. Dynamically responsive biophysical and biochemical stimuli and spatiotemporally controlled architecture may become the main direction of design and preparation of functional hydrogels to realize the complete functionality for TE applications.

\section{AUTHOR CONTRIBUTIONS}

All authors listed have made a substantial, direct and intellectual contribution to the work, and approved it for publication.

\section{ACKNOWLEDGMENTS}

This work was supported by JSPS KAKENHI Grant Number $15 \mathrm{H} 03027$ and 18K19947.

\section{REFERENCES}

Abbadessa, A., Blokzijl, M. M., Mouser, V., Marica, P., Malda, J., Hennink, W., et al. (2016). A thermo-responsive and photo-polymerizable chondroitin sulfatebased hydrogel for 3D printing applications. Carbohydr. Polym. 149, 163-174. doi: 10.1016/j.carbpol.2016.04.080

Annabi, N., Nichol, J. W., Zhong, X., Ji, C., Koshy, S., Khademhosseini, A., et al. (2010). Controlling the porosity and microarchitecture of hydrogels for tissue engineering. Tissue Eng. B Rev. 16, 371-383. doi: 10.1089/ten.teb.2009.0639

Arakawa, C. K., Badeau, B. A., Zheng, Y., and DeForest, C. A. (2017). Multicellular vascularized engineered tissues through user-programmable biomaterial photodegradation. Adv. Mat. 29:1703156. doi: 10.1002/adma.201703156 
Ashraf, S., Park, H.-K., Park, H., and Lee, S.-H. (2016). Snapshot of phase transition in thermoresponsive hydrogel PNIPAM: role in drug delivery and tissue engineering. Macromol. Res. 24, 297-304. doi: 10.1007/s13233-016$4052-2$

Baei, P., Jalili-Firoozinezhad, S., Rajabi-Zeleti, S., Tafazzoli-Shadpour, M., Baharvand, H., and Aghdami, N. (2016). Electrically conductive gold nanoparticle-chitosan thermosensitive hydrogels for cardiac tissue engineering. Mat. Sci. Eng. C 63, 131-141. doi: 10.1016/j.msec.2016. 02.056

Bai, X., Lü, S., Cao, Z., Ni, B., Wang, X., Ning, P., et al. (2017). Dual crosslinked chondroitin sulfate injectable hydrogel formed via continuous Diels-Alder (DA) click chemistry for bone repair. Carbohydr. Polym. 166, 123-130. doi: 10.1016/j.carbpol.2017.02.062

Baker, B. M., and Chen, C. S. (2012). Deconstructing the third dimension-how 3D culture microenvironments alter cellular cues. J. Cell Sci. 125, 3015-3024. doi: $10.1242 /$ jcs. 079509

Balakrishnan, B. (2016). "Injectable hydrogels by chemical crosslinking," in Injectable Hydrogels for Regenerative Engineering, ed. L. S. Nair (Singapore: World Scientific), 155-200.

Balakrishnan, B., Joshi, N., and Banerjee, R. (2013). Borate aided Schiff's base formation yields in situ gelling hydrogels for cartilage regeneration. J. Mater. Chem. B 1, 5564-5577. doi: 10.1039/c3tb21056a

Banerjee, A., Arha, M., Choudhary, S., Ashton, R. S., Bhatia, S. R., Schaffer, D. V., et al. (2009). The influence of hydrogel modulus on the proliferation and differentiation of encapsulated neural stem cells. Biomaterials 30, 4695-4699. doi: 10.1016/j.biomaterials.2009.05.050

Baniasadi, H., Mashayekhan, S., Fadaoddini, S., and Haghirsharifzamini, Y. (2016). Design, fabrication and characterization of oxidized alginate-gelatin hydrogels for muscle tissue engineering applications. J. Biomater. Appl. 31, 152-161. doi: $10.1177 / 0885328216634057$

Bartnikowski, M., Bartnikowski, N., Woodruff, M., Schrobback, K., and Klein, T. (2015). Protective effects of reactive functional groups on chondrocytes in photocrosslinkable hydrogel systems. Acta Biomater. 27, 66-76. doi: 10.1016/j.actbio.2015.08.038

Benton, J. A., DeForest, C. A., Vivekanandan, V., and Anseth, K. S. (2009). Photocrosslinking of gelatin macromers to synthesize porous hydrogels that promote valvular interstitial cell function. Tissue Eng. A 15, 3221-3230. doi: 10.1089/ten.tea.2008.0545

Bian, L., Hou, C., Tous, E., Rai, R., Mauck, R. L., and Burdick, J. A. (2013). The influence of hyaluronic acid hydrogel crosslinking density and macromolecular diffusivity on human MSC chondrogenesis and hypertrophy. Biomaterials 34, 413-421. doi: 10.1016/j.biomaterials.2012.09.052

Bryant, S. J., Bender, R. J., Durand, K. L., and Anseth, K. S. (2004). Encapsulating chondrocytes in degrading PEG hydrogels with high modulus: engineering gel structural changes to facilitate cartilaginous tissue production. Biotechnol. Bioeng. 86, 747-755. doi: 10.1002/bit.20160

Bryant, S. J., Nuttelman, C. R., and Anseth, K. S. (2000). Cytocompatibility of UV and visible light photoinitiating systems on cultured NIH/3T3 fibroblasts in vitro. J. Biomater. Sci. Polym. Ed. 11, 439-457. doi: 10.1163/1568562007 43805

Carmeliet, P., and Jain, R. K. (2000). Angiogenesis in cancer and other diseases. Nature 407:249. doi: 10.1038/35025220

Chaudhuri, O., Gu, L., Darnell, M., Klumpers, D., Bencherif, S. A., Weaver, J. C., et al. (2015). Substrate stress relaxation regulates cell spreading. Nat. Commun. 6:6365. doi: $10.1038 /$ ncomms7365

Chaudhuri, O., Gu, L., Klumpers, D., Darnell, M., Bencherif, S. A., Weaver, J. C., et al. (2016). Hydrogels with tunable stress relaxation regulate stem cell fate and activity. Nat. Mater. 15:326. doi: 10.1038/nmat4489

Cheaburu Yilmaz, C. N., Pamfil, D., Vasile, C., Bibire, N., Lupuşoru, R.-V., Zamfir, C.-L., et al. (2017). Toxicity, biocompatibility, pH-responsiveness and methotrexate release from PVA/hyaluronic acid cryogels for psoriasis therapy. Polymers 9:123. doi: 10.3390/polym9040123

Chen, G., and Kawazoe, N. (2016a). "Polymeric and biomimetic ECM scaffolds for tissue engineering," in Polymeric Biomaterials for Tissue Regeneration, ed. C. Gao (Singapore: Springer), 41-56.

Chen, G., and Kawazoe, N. (2016b). "Preparation of polymer scaffolds by ice particulate method for tissue engineering," in Biomaterials Nanoarchitectonics, ed. M. Ebara (Amsterdam: Elsevier), 77-95.
Chen, G., Kawazoe, N., and Ito, Y. (2018). “Photo-crosslinkable hydrogels for tissue engineering applications," in Photochemistry for Biomedical Applications, ed. Y. Ito (Singapore: Springer), 277-300.

Chen, S., Zhang, Q., Nakamoto, T., Kawazoe, N., and Chen, G. (2016). Gelatin scaffolds with controlled pore structure and mechanical property for cartilage tissue engineering. Tissue Eng. C Methods 22, 189-198. doi: $10.1089 /$ ten.tec.2015.0281

Chen, T., Small, D. A., McDermott, M. K., Bentley, W. E., and Payne, G. F. (2003). Enzymatic methods for in situ cell entrapment and cell release. Biomacromolecules 4, 1558-1563. doi: 10.1021/bm034145k

Chung, C., and Burdick, J. A. (2008). Influence of three-dimensional hyaluronic acid microenvironments on mesenchymal stem cell chondrogenesis. Tissue Eng. A 15, 243-254. doi: 10.1089/ten.tea.2008.0067

Darnell, M. C., Sun, J. Y., Mehta, M., Johnson, C., Arany, P. R., Suo, Z., et al. (2013). Performance and biocompatibility of extremely tough alginate/polyacrylamide hydrogels. Biomaterials 34, 8042-8048. doi: 10.1016/j.biomaterials.2013. 06.061

DeForest, C. A., and Tirrell, D. A. (2015). A photoreversible protein-patterning approach for guiding stem cell fate in three-dimensional gels. Nat. Mater. 14:523. doi: $10.1038 /$ nmat4219

Dragan, E. S. (2014). Design and applications of interpenetrating polymer network hydrogels. A review. Chem. Eng. J. 243, 572-590. doi: 10.1016/j.cej.2014.01.065

Drury, J. L., and Mooney, D. J. (2003). Hydrogels for tissue engineering: scaffold design variables and applications. Biomaterials 24, 4337-4351. doi: 10.1016/S0142-9612(03)00340-5

Eke, G., Mangir, N., Hasirci, N., MacNeil, S., and Hasirci, V. (2017). Development of a UV crosslinked biodegradable hydrogel containing adipose derived stem cells to promote vascularization for skin wounds and tissue engineering. Biomaterials 129, 188-198. doi: 10.1016/j.biomaterials.2017.03.021

Engler, A. J., Sen, S., Sweeney, H. L., and Discher, D. E. (2006). Matrix elasticity directs stem cell lineage specification. Cell 126, 677-689. doi: $10.1016 /$ j.cell.2006.06.044

Fan, C., and Wang, D. A. (2015). Effects of permeability and living space on cell fate and neo-tissue development in hydrogel-based scaffolds: a study with cartilaginous model. Macromol. Biosci. 15, 535-545. doi: 10.1002/mabi.201400453

Fan, M., Ma, Y., Zhang, Z., Mao, J., Tan, H., and Hu, X. (2015a). Biodegradable hyaluronic acid hydrogels to control release of dexamethasone through aqueous Diels-Alder chemistry for adipose tissue engineering. Mater. Sci. Eng. C 56, 311-317. doi: 10.1016/j.msec.2015.04.004

Fan, M., Zhang, Z., Mao, J., and Tan, H. (2015b). Injectable multi-arm poly (ethylene glycol)/hyaluronic acid hydrogels for adipose tissue engineering. J. Macromol. Sci. A 52, 345-352. doi: 10.1080/10601325.2015.1018804

Fedorovich, N. E., Oudshoorn, M. H., van Geemen, D., Hennink, W. E., Alblas, J., and Dhert, W. J. (2009). The effect of photopolymerization on stem cells embedded in hydrogels. Biomaterials 30, 344-353. doi: 10.1016/j.biomaterials.2008.09.037

Feng, Q., Lin, S., Zhang, K., Dong, C., Wu, T., Huang, H., et al. (2017). Sulfated hyaluronic acid hydrogels with retarded degradation and enhanced growth factor retention promote hMSC chondrogenesis and articular cartilage integrity with reduced hypertrophy. Acta Biomater. 53, 329-342. doi: 10.1016/j.actbio.2017.02.015

Feng, Q., Wei, K., Lin, S., Xu, Z., Sun, Y., Shi, P., et al. (2016). Mechanically resilient, injectable, and bioadhesive supramolecular gelatin hydrogels crosslinked by weak host-guest interactions assist cell infiltration and in situ tissue regeneration. Biomaterials 101, 217-228. doi: 10.1016/j.biomaterials.2016.05.043

Fu, S., Dong, H., Deng, X., Zhuo, R., and Zhong, Z. (2017). Injectable hyaluronic acid/poly (ethylene glycol) hydrogels crosslinked via strainpromoted azide-alkyne cycloaddition click reaction. Carbohydr. Polym. 169, 332-340. doi: 10.1016/j.carbpol.2017.04.028

Fukui, T., Kitamura, N., Kurokawa, T., Yokota, M., Kondo, E., Gong, J. P., et al. (2014). Intra-articular administration of hyaluronic acid increases the volume of the hyaline cartilage regenerated in a large osteochondral defect by implantation of a double-network gel. J. Mater. Sci. Mater. Med. 25, 1173-1182. doi: 10.1007/s10856-013-5139-3

Gacesa, P. (1988). Alginates. Carbohydr. Polym. 8, 161-182. doi: 10.1016/0144-8617(88)90001-X 
Gaharwar, A. K., Dammu, S. A., Canter, J. M., Wu, C. J., and Schmidt, G. (2011). Highly extensible, tough, and elastomeric nanocomposite hydrogels from poly (ethylene glycol) and hydroxyapatite nanoparticles. Biomacromolecules 12, 1641-1650. doi: 10.1021/bm200027z

Gao, G., Schilling, A. F., Hubbell, K., Yonezawa, T., Truong, D., Hong, Y., et al. (2015). Improved properties of bone and cartilage tissue from 3D inkjet-bioprinted human mesenchymal stem cells by simultaneous deposition and photocrosslinking in PEG-GelMA. Biotechnol. Lett. 37, 2349-2355. doi: 10.1007/s10529-015-1921-2

Gombotz, W. R., and Wee, S. F. (2012). Protein release from alginate matrices. Adv. Drug Deliv. Rev. 64, 194-205. doi: 10.1016/j.addr.2012.09.007

Gong, J. P., Katsuyama, Y., Kurokawa, T., and Osada, Y. (2003). Double-network hydrogels with extremely high mechanical strength. Adv. Mater. 15, 1155-1158. doi: 10.1002/adma.200304907

Goosen, M. F., O’Shea, G. M., Gharapetian, H. M., Chou, S., and Sun, A. M. (1985). Optimization of microencapsulation parameters: semipermeable microcapsules as a bioartificial pancreas. Biotechnol. Bioeng. 27, 146-150. doi: 10.1002/bit.260270207

Guan, X., Avci-Adali, M., Alarçin, E., Cheng, H., Kashaf, S. S., Li, Y., et al. (2017). Development of hydrogels for regenerative engineering. Biotechnol. J. 12:1600394. doi: 10.1002/biot.201600394

Han, L., Xu, J., Lu, X., Gan, D., Wang, Z., Wang, K., et al. (2017). Biohybrid methacrylated gelatin/polyacrylamide hydrogels for cartilage repair. J. Mater. Chem. B 5, 731-741. doi: 10.1039/C6TB02348G

Han, L. H., Lai, J. H., Yu, S., and Yang, F. (2013). Dynamic tissue engineering scaffolds with stimuli-responsive macroporosity formation. Biomaterials 34, 4251-4258. doi: 10.1016/j.biomaterials.2013.02.051

Haq, M. A., Su, Y., and Wang, D. (2017). Mechanical properties of PNIPAM based hydrogels: a review. Mater. Sci. Eng. C 70, 842-855. doi: 10.1016/j.msec.2016.09.081

Haque, M. A., Kurokawa, T., and Gong, J. P. (2012). Super tough double network hydrogels and their application as biomaterials. Polymer 53, 1805-1822. doi: 10.1016/j.polymer.2012.03.013

Hassan, C. M., and Peppas, N. A. (2000). "Structure and applications of poly (vinyl alcohol) hydrogels produced by conventional crosslinking or by freezing/thawing methods," in Biopolymers. PVA Hydrogels, Anionic Polymerisation Nanocomposites, ed. D. Y. Godovsky (Berlin: Springer), 37-65.

Hassanzadeh, P., Kazemzadeh-Narbat, M., Rosenzweig, R., Zhang, X., Khademhosseini, A., Annabi, N., et al. (2016). Ultrastrong and flexible hybrid hydrogels based on solution self-assembly of chitin nanofibers in gelatin methacryloyl (GelMA). J. Mater. Chem. B 4, 2539-2543. doi: 10.1039/C6TB00021E

Hennink, W., and Van Nostrum, C. F. (2012). Novel crosslinking methods to design hydrogels. Adv. Drug Deliv. Rev. 64, 223-236. doi: 10.1016/j.addr.2012.09.009

Heo, J., Koh, R. H., Shim, W., Kim, H. D., Yim, H. G., and Hwang, N. S. (2016). Riboflavin-induced photo-crosslinking of collagen hydrogel and its application in meniscus tissue engineering. Drug Deliv. Transl. Res. 6, 148-158. doi: 10.1007/s13346-015-0224-4

Ho, S. S., Vollmer, N. L., Refaat, M. I., Jeon, O., Alsberg, E., Lee, M. A., et al. (2016). Bone morphogenetic protein-2 promotes human mesenchymal stem cell survival and resultant bone formation when entrapped in photocrosslinked alginate hydrogels. Adv. Healthc. Mater. 5, 2501-2509. doi: 10.1002/adhm.201600461

Hoffman, A. S. (2012). Hydrogels for biomedical applications. Adv. Drug Deliv. Rev. 64, 18-23. doi: 10.1016/j.addr.2012.09.010

Hoyle, C. E., and Bowman, C. N. (2010). Thiol-ene click chemistry. Angew. Chem. Int. Ed. 49, 1540-1573. doi: 10.1002/anie.200903924

Hsieh, F.-Y., Tao, L., Wei, Y., and Hsu, S.-H. (2017). A novel biodegradable selfhealing hydrogel to induce blood capillary formation. Npg Asia Mater. 9:e363. doi: 10.1038/am.2017.23

Huebsch, N., Arany, P. R., Mao, A. S., Shvartsman, D., Ali, O. A., Bencherif, S. A., et al. (2010). Harnessing traction-mediated manipulation of the cell/matrix interface to control stem-cell fate. Nat. Mater. 9:518. doi: 10.1038/nmat2732

Huettner, N., Dargaville, T. R., and Forget, A. (2018). Discovering cell-adhesion peptides in tissue engineering: beyond RGD. Trends Biotechnol. 6, 372-383. doi: 10.1016/j.tibtech.2018.01.008
Hunt, N. C., Hallam, D., Karimi, A., Mellough, C. B., Chen, J., Steel, D. H., et al. (2017). 3D culture of human pluripotent stem cells in RGD-alginate hydrogel improves retinal tissue development. Acta Biomater. 49, 329-343. doi: 10.1016/j.actbio.2016.11.016

Izadifar, M., Chapman, D., Babyn, P., Chen, X., and Kelly, M. E. (2018). UV-assisted 3D bioprinting of nanoreinforced hybrid cardiac patch for myocardial tissue engineering. Tissue Eng. C Methods 24, 74-88. doi: 10.1089/ten.tec.2017.0346

Jaiswal, M. K., Xavier, J. R., Carrow, J. K., Desai, P., Alge, D., and Gaharwar, A. K. (2015). Mechanically stiff nanocomposite hydrogels at ultralow nanoparticle content. ACS Nano 10, 246-256. doi: 10.1021/acsnano.5b03918

Jiang, H., Qin, S., Dong, H., Lei, Q., Su, X., Zhuo, R., et al. (2015). An injectable and fast-degradable poly (ethylene glycol) hydrogel fabricated via bioorthogonal strain-promoted azide-alkyne cycloaddition click chemistry. Soft Matter 11, 6029-6036. doi: 10.1039/C5SM00508F

Jin, R., Teixeira, L. M., Krouwels, A., Dijkstra, P. J., Van Blitterswijk, C., Karperien, M., et al. (2010). Synthesis and characterization of hyaluronic acid-poly (ethylene glycol) hydrogels via Michael addition: an injectable biomaterial for cartilage repair. Acta Biomater. 6, 1968-1977. doi: 10.1016/j.actbio.2009.12.024

Jo, H., Sim, M., Kim, S., Yang, S., Yoo, Y., Park, J.-H., et al. (2017). Electrically conductive graphene/polyacrylamide hydrogels produced by mild chemical reduction for enhanced myoblast growth and differentiation. Acta Biomater. 48, 100-109. doi: 10.1016/j.actbio.2016.10.035

Kharkar, P. M., Kiick, K. L., and Kloxin, A. M. (2013). Designing degradable hydrogels for orthogonal control of cell microenvironments. Chem. Soc. Rev. 42, 7335-7372. doi: 10.1039/C3CS60040H

Khetan, S., Guvendiren, M., Legant, W. R., Cohen, D. M., Chen, C. S., and Burdick, J. A. (2013). Degradation-mediated cellular traction directs stem cell fate in covalently crosslinked three-dimensional hydrogels. Nat. Mater. 12:458. doi: $10.1038 /$ nmat3586

Kim, D. H., Martin, J. T., Elliott, D. M., Smith, L. J., and Mauck, R. L. (2015). Phenotypic stability, matrix elaboration and functional maturation of nucleus pulposus cells encapsulated in photocrosslinkable hyaluronic acid hydrogels. Acta Biomater. 12, 21-29. doi: 10.1016/j.actbio.2014.10.030

Kim, S., Cui, Z. K., Fan, J., Fartash, A., Aghaloo, T. L., and Lee, M. (2016). Photocrosslinkable chitosan hydrogels functionalized with the RGD peptide and phosphoserine to enhance osteogenesis. J. Mater. Chem. B 4, 5289-5298. doi: 10.1039/C6TB01154C

Kloxin, A. M., Tibbitt, M. W., Kasko, A. M., Fairbairn, J. A., and Anseth, K. S. (2010). Tunable hydrogels for external manipulation of cellular microenvironments through controlled photodegradation. Adv. Mater. 22, 61-66. doi: 10.1002/adma.200900917

Knudson, C. B., and Knudson, W. (2004). Hyaluronan and CD44: modulators of chondrocyte metabolism. Clin. Orthop. Relat. Res. 427, S152-S162. doi: 10.1097/01.blo.0000143804.26638.82

Koh, R. H., Jin, Y., Kang, B. J., and Hwang, N. S. (2017). Chondrogenically primed tonsil-derived mesenchymal stem cells encapsulated in riboflavininduced photocrosslinking collagen-hyaluronic acid hydrogel for meniscus tissue repairs. Acta Biomater. 53, 318-328. doi: 10.1016/j.actbio.2017. 01.081

Le Thi, P., Lee, Y., Nguyen, D. H., and Park, K. D. (2017). In situ forming gelatin hydrogels by dual-enzymatic cross-linking for enhanced tissue adhesiveness. J. Mater. Chem. B 5, 757-764. doi: 10.1039/C6TB02179D

Lee, H. P., Gu, L., Mooney, D. J., Levenston, M. E., and Chaudhuri, O. (2017). Mechanical confinement regulates cartilage matrix formation by chondrocytes. Nat. Mater. 16:1243. doi: 10.1038/nmat4993

Lee, J. B., Wang, X., Faley, S., Baer, B., Balikov, D. A., Sung, H. J., et al. (2016). Development of 3D microvascular networks within gelatin hydrogels using thermoresponsive sacrificial microfibers. Adv. Healthc. Mater. 5, 781-785. doi: 10.1002/adhm.201500792

Lee, T. T., García, J. R., Paez, J. I., Singh, A., Phelps, E. A., Weis, S., et al. (2015). Light-triggered in vivo activation of adhesive peptides regulates cell adhesion, inflammation and vascularization of biomaterials. Nat. Mater. 14:352. doi: $10.1038 / \mathrm{nmat} 4157$

Lee, V. K., Kim, D. Y., Ngo, H., Lee, Y., Seo, L., Yoo, S. S., et al. (2014). Creating perfused functional vascular channels using 3D bio-printing technology. Biomaterials 35, 8092-8102. doi: 10.1016/j.biomaterials.2014.05.083 
Leong, W., Kremer, A., and Wang, D. A. (2016). Development of size-customized hepatocarcinoma spheroids as a potential drug testing platform using a sacrificial gelatin microsphere system. Mater. Sci. Eng. C 63, 644-649. doi: 10.1016/j.msec.2016.03.046

Levett, P. A., Melchels, F. P., Schrobback, K., Hutmacher, D. W., Malda, J., and Klein, T. J. (2014). A biomimetic extracellular matrix for cartilage tissue engineering centered on photocurable gelatin, hyaluronic acid and chondroitin sulfate. Acta Biomater. 10, 214-223. doi: 10.1016/j.actbio.2013. 10.005

Lewandowska-Łancucka, J., Mystek, K., Mignon, A., Van Vlierberghe, S., Łatkiewicz, A., and Nowakowska, M. (2017). Alginate-and gelatinbased bioactive photocross-linkable hybrid materials for bone tissue engineering. Carbohydr. Polym. 157, 1714-1722. doi: 10.1016/j.carbpol.2016. 11.051

Li, X., Chen, S., Li, J., Wang, X., Zhang, J., Kawazoe, N., et al. (2016). 3D culture of chondrocytes in gelatin hydrogels with different stiffness. Polymers 8:269. doi: 10.3390/polym8080269

Li, X., Chen, Y., Kawazoe, N., and Chen, G. (2017a). Influence of microporous gelatin hydrogels on chondrocyte functions. J. Mater. Chem. B 5, 5753-5762. doi: 10.1039/C7TB01350G

Li, X., Zhang, J., Kawazoe, N., and Chen, G. (2017b). Fabrication of highly crosslinked gelatin hydrogel and its influence on chondrocyte proliferation and phenotype. Polymers 9:309. doi: 10.3390/polym9080309

Liu, Y., and Chan-Park, M. B. (2009). Hydrogel based on interpenetrating polymer networks of dextran and gelatin for vascular tissue engineering. Biomaterials 30, 196-207. doi: 10.1016/j.biomaterials.2008.09.041

Long, J., Kim, H., Kim, D., Lee, J. B., and Kim, D. H. (2017). A biomaterial approach to cell reprogramming and differentiation. J. Mater. Chem. B 5, 2375-2389. doi: 10.1039/C6TB03130G

Lou, J., Stowers, R., Nam, S., Xia, Y., and Chaudhuri, O. (2018). Stress relaxing hyaluronic acid-collagen hydrogels promote cell spreading, fiber remodeling, and focal adhesion formation in 3D cell culture. Biomaterials 154, 213-222. doi: 10.1016/j.biomaterials.2017.11.004

Lü, S., Bai, X., Liu, H., Ning, P., Wang, Z., Gao, C., et al. (2017). An injectable and self-healing hydrogel with covalent cross-linking in vivo for cranial bone repair. J. Mater. Chem. B 5, 3739-3748. doi: 10.1039/C7TB00776K

Magarinos, A. M., Pedron, S., Creixell, M., Kilinc, M., Tabansky, I., Pfaff, D. W., et al. (2018). The feasibility of encapsulated embryonic medullary reticular cells to grow and differentiate into neurons in functionalized gelatin-based hydrogels. Front. Mater. 5:40. doi: 10.3389/fmats.2018. 00040

Mahadevaiah, S., Robinson, K. G., Kharkar, P. M., Kiick, K. L., and Akins, R. E. (2015). Decreasing matrix modulus of PEG hydrogels induces a vascular phenotype in human cord blood stem cells. Biomaterials 62, 24-34. doi: 10.1016/j.biomaterials.2015.05.021

Mao, H., Kim, S. M., Ueki, M., and Ito, Y. (2017). Serum-free culturing of human mesenchymal stem cells with immobilized growth factors. J. Mater. Chem. B 5, 928-934. doi: 10.1039/C6TB02867E

Martens, P. J., Bryant, S. J., and Anseth, K. S. (2003). Tailoring the degradation of hydrogels formed from multivinyl poly (ethylene glycol) and poly (vinyl alcohol) macromers for cartilage tissue engineering. Biomacromolecules 4, 283-292. doi: 10.1021/bm025666v

Martinsen, A., Skjåk-Bræk, G., and Smidsrød, O. (1989). Alginate as immobilization material: I. Correlation between chemical and physical properties of alginate gel beads. Biotechnol. Bioeng. 33, 79-89. doi: 10.1002/bit.260330111

Mellati, A., Fan, C. M., Tamayol, A., Annabi, N., Dai, S., Bi, J., et al. (2017). Microengineered 3D cell-laden thermoresponsive hydrogels for mimicking cell morphology and orientation in cartilage tissue engineering. Biotechnol. Bioeng. 114, 217-231. doi: 10.1002/bit.26061

Michiels, C. (2003). Endothelial cell functions. J. Cell. Physiol. 196, 430-443. doi: $10.1002 /$ jcp. 10333

Miguel, S. P., Ribeiro, M. P., Brancal, H., Coutinho, P., and Correia, I. J. (2014). Thermoresponsive chitosan-agarose hydrogel for skin regeneration. Carbohydr. Polym. 111, 366-373. doi: 10.1016/j.carbpol.2014. 04.093

Miller, J. S., Stevens, K. R., Yang, M. T., Baker, B. M., Nguyen, D. H. T., Cohen, D. M., et al. (2012). Rapid casting of patterned vascular networks for perfusable engineered three-dimensional tissues. Nat. Mater. 11:768. doi: $10.1038 /$ nmat3357

Nakahata, M., Takashima, Y., Yamaguchi, H., and Harada, A. (2011). Redoxresponsive self-healing materials formed from host-guest polymers. Nat. Commun. 2:511. doi: 10.1038/ncomms1521

Navaei, A., Saini, H., Christenson, W., Sullivan, R. T., Ros, R., and Nikkhah, M. (2016a). Gold nanorod-incorporated gelatin-based conductive hydrogels for engineering cardiac tissue constructs. Acta Biomater. 41, 133-146. doi: 10.1016/j.actbio.2016.05.027

Navaei, A., Truong, D., Heffernan, J., Cutts, J., Brafman, D., Sirianni, R. W., et al. (2016b). PNIPAAm-based biohybrid injectable hydrogel for cardiac tissue engineering. Acta Biomater. 32, 10-23. doi: 10.1016/j.actbio.2015. 12.019

Neumann, A. J., Quinn, T., and Bryant, S. J. (2016). Nondestructive evaluation of a new hydrolytically degradable and photo-clickable PEG hydrogel for cartilage tissue engineering. Acta Biomater. 39, 1-11. doi: 10.1016/j.actbio.2016. 05.015

Nguyen, M. K., and Alsberg, E. (2014). Bioactive factor delivery strategies from engineered polymer hydrogels for therapeutic medicine. Prog. Polym. Sci. 39, 1235-1265. doi: 10.1016/j.progpolymsci.2013.12.001

Omobono, M. A., Zhao, X., Furlong, M. A., Kwon, C. H., Gill, T. J., Randolph, M. A., et al. (2015). Enhancing the stiffness of collagen hydrogels for delivery of encapsulated chondrocytes to articular lesions for cartilage regeneration. J. Biomed. Mater. Res. A 103, 1332-1338. doi: 10.1002/jbm.a. 35266

Pacelli, S., Rampetsreiter, K., Modaresi, S., Subham, S., Chakravarti, A. R., Lohfeld, S., et al. (2018). Fabrication of a double crosslinked interpenetrating polymeric network (IPN) hydrogel surface modified with polydopamine to modulate osteogenic differentiation of adipose-derived stem cells. ACS Appl. Mater. Interfaces. 10, 24955-24962. doi: 10.1021/acsami.8b 05200

Park, Y. D., Tirelli, N., and Hubbell, J. A. (2003). Photopolymerized hyaluronic acid-based hydrogels and interpenetrating networks. Biomaterials 24, 893-900. doi: 10.1016/S0142-9612(02)00420-9

Parker, J., Mitrousis, N., and Shoichet, M. S. (2016). Hydrogel for simultaneous tunable growth factor delivery and enhanced viability of encapsulated cells in vitro. Biomacromolecules 17, 476-484. doi: 10.1021/acs.biomac. 5 b01366

Peng, Y., Liu, Q., He, T., Ye, K., Yao, X., and Ding, J. (2018). Degradation rate affords a dynamic cue to regulate stem cells beyond varied matrix stiffness. Biomaterials 78, 467-480. doi: 10.1016/j.biomaterials.2018. 04.021

Ren, K., He, C., Xiao, C., Li, G., and Chen, X. (2015). Injectable glycopolypeptide hydrogels as biomimetic scaffolds for cartilage tissue engineering. Biomaterials 51, 238-249. doi: 10.1016/j.biomaterials.2015.02.026

Rizwan, M., Peh, G. S., Ang, H. P., Lwin, N. C., Adnan, K., Mehta, J. S., et al. (2017). Sequentially-crosslinked bioactive hydrogels as nanopatterned substrates with customizable stiffness and degradation for corneal tissue engineering applications. Biomaterials 120, 139-154. doi: 10.1016/j.biomaterials.2016.12.026

Rodell, C. B., Highley, C. B., Chen, M. H., Dusaj, N. N., Wang, C., Han, L., et al. (2016). Evolution of hierarchical porous structures in supramolecular guest-host hydrogels. Soft Matter 12, 7839-7847. doi: 10.1039/C6SM $01395 \mathrm{C}$

Ruoslahti, E., and Pierschbacher, M. D. (1987). New perspectives in cell adhesion: RGD and integrins. Science 238, 491-498. doi: 10.1126/science. 2821619

Salinas, C. N., and Anseth, K. S. (2008). The enhancement of chondrogenic differentiation of human mesenchymal stem cells by enzymatically regulated RGD functionalities. Biomaterials 29, 2370-2377. doi: 10.1016/j.biomaterials.2008.01.035

Schuh, E., Hofmann, S., Stok, K., Notbohm, H., Müller, R., and Rotter, N. (2012). Chondrocyte redifferentiation in 3D: the effect of adhesion site density and substrate elasticity. J. Biomed. Mater. Res. A 100, 38-47. doi: 10.1002/jbm.a.33226

Sheehy, E. J., Vinardell, T., Buckley, C. T., and Kelly, D. J. (2013). Engineering osteochondral constructs through spatial regulation of endochondral ossification. Acta Biomater. 9, 5484-5492. doi: 10.1016/j.actbio.2012.11.008 
Shendi, D., Dede, A., Yin, Y., Wang, C., Valmikinathan, C., and Jain, A. (2016). Tunable, bioactive protein conjugated hyaluronic acid hydrogel for neural engineering applications. J. Mater. Chem. B 4, 2803-2818. doi: 10.1039/C5TB02235E

Shin, S. R., Jung, S. M., Zalabany, M., Kim, K., Zorlutuna, P., and Kim, S. B., et al. (2013). Carbon-nanotube-embedded hydrogel sheets for engineering cardiac constructs and bioactuators. ACS Nano 7, 2369-2380. doi: 10.1021/nn305559j

Skaalure, S. C., Dimson, S. O., Pennington, A. M., and Bryant, S. J. (2014). Semi-interpenetrating networks of hyaluronic acid in degradable PEG hydrogels for cartilage tissue engineering. Acta Biomater. 10, 3409-3420. doi: 10.1016/j.actbio.2014.04.013

Slaughter, B. V., Khurshid, S. S., Fisher, O. Z., Khademhosseini, A., and Peppas, N. A. (2009). Hydrogels in regenerative medicine. Adv. Mater. 21, 3307-3329. doi: 10.1002/adma.200802106

Sridhar, B. V., Brock, J. L., Silver, J. S., Leight, J. L., Randolph, M. A., and Anseth, K. S. (2015). Development of a cellularly degradable PEG hydrogel to promote articular cartilage extracellular matrix deposition. Adv. Healthc. Mater. 4, 702-713. doi: 10.1002/adhm.201400695

Sridhar, B. V., Doyle, N. R., Randolph, M. A., and Anseth, K. S. (2014). Covalently tethered TGF- $\beta 1$ with encapsulated chondrocytes in a PEG hydrogel system enhances extracellular matrix production. J. Biomed. Mater. Res. A 102, 4464-4472. doi: 10.1002/jbm.a.35115

Steed, J. W., Turner, D. R., and Wallace, K. (2007). Core Concepts in Supramolecular Chemistry and Nanochemistry. Chichester: John Wiley \& Sons.

Steinmetz, N. J., Aisenbrey, E. A., Westbrook, K. K., Qi, H. J., and Bryant, S. J. (2015). Mechanical loading regulates human MSC differentiation in a multi-layer hydrogel for osteochondral tissue engineering. Acta Biomater. 21, 142-153. doi: 10.1016/j.actbio.2015.04.015

Steinmetz, N. J., and Bryant, S. J. (2011). The effects of intermittent dynamic loading on chondrogenic and osteogenic differentiation of human marrow stromal cells encapsulated in RGD-modified poly (ethylene glycol) hydrogels. Acta Biomater. 7, 3829-3840. doi: 10.1016/j.actbio.2011.06.031

Stevens, K. R., Ungrin, M., Schwartz, R., Ng, S., Carvalho, B., Christine, K., et al. (2013). InVERT molding for scalable control of tissue microarchitecture. Nat. Commun. 4:1847. doi: 10.1038/ncomms 2853

Stüdle, C., Vallmajó-Martín, Q., Haumer, A., Guerrero, J., Centola, M., Mehrkens, A., et al. (2018). Spatially confined induction of endochondral ossification by functionalized hydrogels for ectopic engineering of osteochondral tissues. Biomaterials 171, 219-229. doi: 10.1016/j.biomaterials.2018.04.025

Sun, J., Wei, D., Yang, K., Yang, Y., Liu, X., Fan, H., et al. (2017). The development of cell-initiated degradable hydrogel based on methacrylated alginate applicable to multiple microfabrication technologies. J. Mater. Chem. B 5, 8060-8069. doi: $10.1039 /$ C7TB01458A

Taylor, D. L., and in het Panhuis, M. (2016). Self-healing hydrogels. Adv. Mater. 28, 9060-9093. doi: 10.1002/adma.201601613

Tibbitt, M. W., and Anseth, K. S. (2009). Hydrogels as extracellular matrix mimics for 3D cell culture. Biotechnol. Bioeng. 103, 655-663. doi: 10.1002/bit.22361

Tocchio, A., Tamplenizza, M., Martello, F., Gerges, I., Rossi, E., Argentiere, S., et al. (2015). Versatile fabrication of vascularizable scaffolds for large tissue engineering in bioreactor. Biomaterials 45, 124-131. doi: $10.1016 /$ j.biomaterials.2014.12.031

Tseng, T. C., Tao, L., Hsieh, F. Y., Wei, Y., Chiu, I. M., and Hsu, S. H. (2015). An injectable, self-healing hydrogel to repair the central nervous system. $A d v$. Mater. 27, 3518-3524. doi: 10.1002/adma.201500762

Ulijn, R. V. (2006). Enzyme-responsive materials: a new class of smart biomaterials. J. Mater. Chem. 16, 2217-2225. doi: 10.1039/b601776m

Vo, T. N., Shah, S., Lu, S., Tatara, A., Lee, E., Roh, T., et al. (2016). Injectable dualgelling cell-laden composite hydrogels for bone tissue engineering. Biomaterials 83, 1-11. doi: 10.1016/j.biomaterials.2015.12.026

Wang, J., Zhang, F., Tsang, W. P., Wan, C., and Wu, C. (2017a). Fabrication of injectable high strength hydrogel based on 4-arm star PEG for cartilage tissue engineering. Biomaterials 120, 11-21. doi: 10.1016/j.biomaterials.2016. 12.015

Wang, L. S., Du, C., Toh, W. S., Wan, A. C., Gao, S. J., and Kurisawa, M. (2014). Modulation of chondrocyte functions and stiffness-dependent cartilage repair using an injectable enzymatically crosslinked hydrogel with tunable mechanical properties. Biomaterials 35, 2207-2217. doi: 10.1016/j.biomaterials.2013. 11.070
Wang, X., Li, Z., Shi, T., Zhao, P., An, K., Lin, C., et al. (2017b). Injectable dextran hydrogels fabricated by metal-free click chemistry for cartilage tissue engineering. Mater. Sci. Eng. C 73, 21-30. doi: 10.1016/j.msec.2016. 12.053

Wei, D., Sun, J., Bolderson, J., Zhong, M., Dalby, M. J., Cusack, M., et al. (2017). Continuous fabrication and assembly of spatial cell-laden fibers for a tissue-like construct via a photolithographic-based microfluidic chip. ACS Appl. Mater. Interfaces 9, 14606-14617. doi: 10.1021/acsami.7b 00078

Wei, K., Zhu, M., Sun, Y., Xu, J., Feng, Q., Lin, S., et al. (2016). Robust biopolymeric supramolecular "host- guest macromer" hydrogels reinforced by in situ formed multivalent nanoclusters for cartilage regeneration. Macromolecules 49, 866-875. doi: 10.1021/acs.macromol.5b02527

Wen, J. H., Vincent, L. G., Fuhrmann, A., Choi, Y. S., Hribar, K. C., Taylor-Weiner, H., et al. (2014). Interplay of matrix stiffness and protein tethering in stem cell differentiation. Nat. Mater. 13:979. doi: 10.1038/nmat4051

Xavier, J. R., Thakur, T., Desai, P., Jaiswal, M. K., Sears, N., Cosgriff-Hernandez, E., et al. (2015). Bioactive nanoengineered hydrogels for bone tissue engineering: a growth-factor-free approach. ACS Nano 9, 3109-3118. doi: 10.1021/nn5 $07488 \mathrm{~s}$

Xu, J., Feng, E., and Song, J. (2014). Bioorthogonally cross-linked hydrogel network with precisely controlled disintegration time over a broad range. J. Am. Chem. Soc. 136, 4105-4108. doi: 10.1021/ja4130862

Xu, Z., and Bratlie, K. M. (2018). Click chemistry and material selection for in situ fabrication of hydrogels in tissue engineering applications. ACS Biomater. Sci. Eng. 4, 2276-2291. doi: 10.1021/acsbiomaterials.8b00230

Yan, H. J., Casalini, T., Hulsart-Billström, G., Wang, S., Oommen, O. P., Salvalaglio, M., et al. (2018). Synthetic design of growth factor sequestering extracellular matrix mimetic hydrogel for promoting in vivo bone formation. Biomaterials 161, 190-202. doi: 10.1016/j.biomaterials.2018.01.041

Yang, G., Lin, H., Rothrauff, B. B., Yu, S., and Tuan, R. S. (2016). Multilayered polycaprolactone/gelatin fiber-hydrogel composite for tendon tissue engineering. Acta Biomater. 35, 68-76. doi: 10.1016/j.actbio.2016. 03.004

Yang, Y., Wang, X., Yang, F., Wang, L., and Wu, D. (2018). Highly elastic and ultratough hybrid ionic-covalent hydrogels with tunable structures and mechanics. Adv. Mater. 30:1707071. doi: 10.1002/adma.2017 07071

Yasuda, K., Kitamura, N., Gong, J. P., Arakaki, K., Kwon, H. J., Onodera, S., et al. (2009). A novel double-network hydrogel induces spontaneous articular cartilage regeneration in vivo in a large osteochondral defect. Macromol. Biosci. 9, 307-316. doi: 10.1002/mabi.200800223

You, S., Li, J., Zhu, W., Yu, C., Mei, D., and Chen, S. (2018). Nanoscale 3D printing of hydrogels for cellular tissue engineering. J. Mater. Chem. B 6, 2187-2197. doi: 10.1039/C8TB00301G

Yue, K., Trujillo-de Santiago, G., Alvarez, M. M., Tamayol, A., Annabi, N., and Khademhosseini, A. (2015). Synthesis, properties, and biomedical applications of gelatin methacryloyl (GelMA) hydrogels. Biomaterials 73, 254-271. doi: 10.1016/j.biomaterials.2015.08.045

Zhang, B., Montgomery, M., Chamberlain, M. D., Ogawa, S., Korolj, A., Pahnke, A., et al. (2016). Biodegradable scaffold with built-in vasculature for organon-a-chip engineering and direct surgical anastomosis. Nat. Mater. 15:669. doi: $10.1038 /$ nmat 4570

Zhang, Q., Lu, H., Kawazoe, N., and Chen, G. (2014). Pore size effect of collagen scaffolds on cartilage regeneration. Acta Biomater. 10, 2005-2013. doi: 10.1016/j.actbio.2013.12.042

Zhang, X., Xu, B., Puperi, D. S., Yonezawa, A. L., Wu, Y., Tseng, H., et al. (2015). Integrating valve-inspired design features into poly (ethylene glycol) hydrogel scaffolds for heart valve tissue engineering. Acta Biomater. 14, 11-21. doi: 10.1016/j.actbio.2014.11.042

Zhao, X., Huebsch, N., Mooney, D. J., and Suo, Z. (2010). Stress-relaxation behavior in gels with ionic and covalent crosslinks. J. Appl. Phys. 107:063509. doi: $10.1063 / 1.3343265$

Zhao, X., Lang, Q., Yildirimer, L., Lin, Z. Y., Cui, W., Annabi, N., et al. (2016). Photocrosslinkable gelatin hydrogel for epidermal tissue engineering. $A d v$. Healthc. Mater. 5, 108-118. doi: 10.1002/adhm.201500005

Zhu, Y., Wu, H., Sun, S., Zhou, T., Wu, J., and Wan, Y. (2014). Designed composites for mimicking compressive mechanical properties of 
articular cartilage matrix. J. Mech. Behav. Biomed. Mater. 36, 32-46. doi: 10.1016/j.jmbbm.2014.04.003

Zieris, A., Prokoph, S., Levental, K. R., Welzel, P. B., Grimmer, M., Freudenberg, U., et al. (2010). FGF-2 and VEGF functionalization of starPEG-heparin hydrogels to modulate biomolecular and physical cues of angiogenesis. Biomaterials 31, 7985-7994. doi: 10.1016/j.biomaterials.2010. 07.021

Zuo, Y., Liu, X., Wei, D., Sun, J., Xiao, W., Zhao, H., et al. (2015). Photocross-linkable methacrylated gelatin and hydroxyapatite hybrid hydrogel for modularly engineering biomimetic osteon. ACS Appl. Mater. Interfaces 7:10386-10394. doi: 10.1021/acsami.5b01433
Conflict of Interest Statement: The authors declare that the research was conducted in the absence of any commercial or financial relationships that could be construed as a potential conflict of interest.

Copyright (c) 2018 Li, Sun, Li, Kawazoe and Chen. This is an open-access article distributed under the terms of the Creative Commons Attribution License (CC BY). The use, distribution or reproduction in other forums is permitted, provided the original author(s) and the copyright owner(s) are credited and that the original publication in this journal is cited, in accordance with accepted academic practice. No use, distribution or reproduction is permitted which does not comply with these terms. 